\title{
A CDS approach to induce facilities-based competition over NGA networks
}

\author{
Markos Tselekounis, Dimitris Varoutas*, Drakoulis Martakos \\ Department of Informatics and Telecommunications, National and Kapodistrian University of Athens, Panepistimiopolis, Ilissia, Athens \\ 15784, Greece
}

\section{A R T I C L E I N F O}

Keywords:

Access regulation

Credit Default Swap (CDS)

Facilities-based competition

Investment incentives

Next Generation Access Networks (NGA)

\begin{abstract}
A B S T R A C T
The current regulatory framework in the European NGA market provides the basic principles for the gradual migration from service-based competition over the legacy copper access networks to facilities-based competition over fiber-based Next Generation Access (NGA) networks. This paper initially reviews the related literature and shows that: (i) an unbundling policy that boosts entry by alternative operators promotes service-based competition but provides operators with disincentives to invest in network upgrade; (ii) there is no consensus about the optimal regulatory policy that promotes competition and encourages investments in NGA networks; and (iii) the reviewed research articles are not consistent with the current regulatory framework in the European NGA market in terms of both the evolution of the regulatory goals over time and the recommended regulatory settings. This paper aims to propose a novel approach in order to effectively meet the current regulatory goals using the recommended settings. It is shown that the proposed approach, which is based on the basic principles governing a Credit Default Swap (CDS), provides an effective migration path towards facilities-based competition over NGA networks.
\end{abstract}

(c) 2013 Elsevier Ltd. All rights reserved.

\section{Introduction}

The Telecommunications Act of 1996 (FCC, 1996) passed by US Congress and administered by the Federal Communications Commission (FCC), as well as, the European Commission's (EC) Regulation on Local Loop Unbundling (EC, 2000) mandated unbundled access to the metallic local loops of incumbent operators at cost-based prices. The short-run goal of this unbundling policy was to reduce the incumbent's market power in order to enable alternative operators (new entrants) to enter the market and compete effectively with the incumbent in the retail (downstream) market. Therefore, operators would compete on their services (service-based competition), and hence, consumers would enjoy the welfare gains from static efficiency (i.e. existing assets are used efficiently and prices are driven towards marginal cost). Armstrong (2002), Valletti (2003) and Vogelsang (2003) summarize the optimal access pricing policy in different static contexts static contexts, in which it is appropriate to apply cost-based access pricing, Ramsey pricing and the Efficient Component Pricing Rule (ECPR).

However, the long-run goal of this unbundling policy was to promote investments in new network infrastructures from the incumbents, and especially entrants. In this case, operators would compete on their facilities (facilities-based

\footnotetext{
* Corresponding author. Tel.: +30 210 7275318; fax: +30 2107275214

E-mail addresses: markos@di.uoa.gr (M. Tselekounis), D.Varoutas@di.uoa.gr, dvaroutas@gmail.com (D. Varoutas), martakos@di.uoa.gr (D. Martakos).
} 
competition) rather than on their services, and hence, consumers would enjoy the welfare gains from dynamic efficiency (i. e. the encouragement of investments in competing infrastructures and the deployment of new technologies). In particular, facilities-based competition is regarded as the only means to achieve sustainable competition (Cave, 2006; Oldale \& Padilla, 2004) since it creates a level playing field between incumbent and entrants (De Bijl \& Peitz, 2002). In addition, a growing number of empirical studies conclude that facilities-based competition has been the main driver for broadband diffusion (Bouckaert, van Dijk, \& Verboven, 2010; Denni \& Gruber, 2007; Distaso, Lupi, \& Manenti, 2006; Höffler, 2007) although they do not find a negative relationship between service-based competition and broadband diffusion. Given that broadband penetration positively affects economic growth (Greenstein \& McDevitt, 2009; Koutroumpis, 2009), it can be deduced that facilities-based competition creates a superior potential for economic growth than does service-based competition.

Many research articles try to model such unbundling practices and assess their effectiveness and efficiency implications both theoretically and empirically. ${ }^{1}$ Using different theoretical models of downstream competition, Foros (2004) and Kotakorpi (2004) show that cost-oriented access prices discourage incumbents to invest in network upgrade unless they are much more efficient than their rivals in the downstream market. Sarmento and Brandao (2007) also find a negative relationship between cost-based access prices and the incumbents' incentives to invest even if the incumbents are partially compensated for the investment cost. Not only the incumbents' investment incentives are negatively affected by costoriented access prices, but also the new entrants' investment decisions are negatively influenced. Valletti (2003) argues that potential entrants, who can free-ride on the incumbent's network, will wait for the incumbent to invest in access infrastructure and then seek access. In addition, Bourreau and Doğan $(2005,2006)$ show that unbundling of the local loop may delay the entrants' investments, even in an unregulated environment. Grajek and Röller (2009) empirically confirm the negative impact of an unbundling policy that boosts entry by alternative operators on incentives to invest in facilities-based competition. In particular, they use a comprehensive panel data set (180 fixed-line operators in 25 European countries observed from December 1997 to December 2006) in order to show that unbundling results in a significant negative effect on the incumbents' incentives to invest in network upgrade, whereas easier access pushes entrants towards service-based competition.

It is thus obvious that cost-based access prices disincentivize both the incumbents and the entrants to invest in network upgrade. On the other hand, cost-based access prices have been proven very effective in promoting static efficiency. Indeed, by analyzing the results of Tselekounis, Varoutas, and Martakos (2012), it can be deduced that when the access is priced at cost, the productively efficient make-or-buy decision undertaken by the entrant is always socially optimal. The main conclusion of the above studies is that an unbundling policy that boosts entry by alternative operators promotes servicebased competition but leads to losses in dynamic efficiency (Bouckaert et al., 2010). This implies that cost-oriented access prices is an effective regulatory tool for fostering service-based competition over the legacy copper access networks, which were largely deployed by public funds, but they cannot promote investments in new fiber-based access infrastructures (the so-called Next Generations Access Networks, or NGAs) by either incumbents or entrants.

However, the need for the deployment of NGA networks is almost imperative. Firstly, the numbers of internet users, as well as, the capacity they demand have increased dramatically during the last decade. As a result, the increasing transmitted volume of data has made the traditional access copper networks incapable of providing end-users with the demanded bandwidth. On the contrary, NGA networks are the only future-proof solution capable to handle future demand (Shumate, 2008) since the transmission capabilities of fiber are theoretically unlimited, whereas it also provides high data rates, low loss and low distortion. Secondly, investments in broadband infrastructure have an indisputable positive effect on broadband diffusion, economic growth, job creation and consumers' welfare (Czernich, Falck, Kretschmer, \& Woessmann, 2011; ITU, 2012; Katz, Vaterlaus, Zenhäusern, \& Suter, 2010; Reynolds, 2009).

These two reasons partially interpret why national governments rank among their top priorities the encouragement of investments in NGA networks rather than the promotion of facilities-based competition. The US government's National Broadband Plan (FCC, 2010) and the European Commission's Digital Agenda for Europe (EC, 2010a) are examples of these perceived political priorities for the diffusion of broadband infrastructure access and services.

Considering the above-mentioned technical and economic issues that make the need for investments in NGA networks imperative, as well as, the inappropriateness of cost-based access prices for promoting such investments, the European Commission (EC) issued a Recommendation on regulated access to NGA (EC, 2010b) providing the National Regulatory Authorities (NRAs) with guidelines for tackling the trade-off between fostering competition and promoting investments with regard to NGA networks. Section 2 discusses the EC Recommendation, as well as, its impact on competition and firms' investment incentives. The main implication of this Recommendation is that the initial regulatory focus is to establish service-based competition over NGA networks, and then to promote facilities-based competition. This implies that regulators should initially tackle the trade-off between encouraging investments in NGA networks and promoting competition. Once service-based competition over NGA networks has been achieved, the disclosed regulatory policy should provide access seekers with incentives to invest in their own network infrastructures in order to be facilities-based competitors.

${ }^{1}$ See Cambini and Jiang (2009) for an excellent review of the theoretical and empirical literature on the relationship between broadband investment and regulation. 
In addition, the ongoing academic research shifts its focus from assessing the effectiveness and efficiency implications of cost-oriented access schemes to proposing new regulatory approaches, and then assessing their efficiency and other performance implications. Thus, Section 3 provides a review of the articles that depart from the main principles governing the regulation of the copper access networks (i.e. permanent regulation of the access at uniform cost-oriented prices) by proposing alternative regulatory settings that may promote both competition and investments in NGA networks.

In fact, there is a major difference between the reviewed research articles and the EC Recommendation. Existing research articles study the impact of alternative regulatory approaches on either an investment leader's or an investment follower's (access seeker) incentives to invest in NGA networks. However, in the former case, the existing studies do not take into account the access seeker's subsequent investment reaction, whereas in the latter case, they assume that the investment leader has already deployed an NGA network. On the contrary, the goal of the EC Recommendation is to propose an access scheme that encourage the initial investor to deploy an NGA network without distorting the competition level, and then to induce the access seekers to act as facilities-based competitors. Therefore, the current regulatory framework in the European NGA market requires a composite (rather than a separate) approach to induce a gradual migration from servicebased competition over copper access networks to facilities-based competition over NGA networks. There are also minor differences between the existing literature and the EC Recommendation mainly in terms of the regulatory settings, such as the characteristics of the access pricing formula, the evolution of the access price over time and the provision of regulatory certainty. It is thus obvious that there is a gap between the existing literature and the current regulatory framework in the European NGA market.

This paper proposes an innovative regulatory approach which not only is consistent with the goal of the EC Recommendation, but also takes into account the recommended regulatory settings. In particular, the proposed approach is based on the basic principles governing a Credit Default Swap (CDS), which is a widely known financial tool for transferring credit risk. Section 4 provides a detailed description of this approach and discusses its impact on investment incentives and competition. The novelty of this approach is twofold. It is the first time that a financial instrument for transferring credit risk (in our case a CDS) is applied to the field of regulatory economics. It should be noted that this is not the first time that a pure financial tool is applied to the information and communications technology (ICT) industries. There is also a well known modification of the call option on a share of stock that aims to better value an ICT investment project. Such modification has led to the deployment of the so-called "real option" methodology. Furthermore, it is the first paper that aims to develop a model that reflects the current regulatory framework in the European NGA market. It is shown that, under plausible assumptions, the proposed approach provides an effective migration path towards facilities-based competition over NGA networks, and hence, resolves the standard trade-off between static and dynamic efficiency.

\section{The current European NGA regulatory framework}

Investment in NGA networks not only requires a high initial fixed cost but also is mainly sunk once the investment has been made. This implies that potential investors are reluctant to invest in NGA networks unless they are reimbursed for the risk they incur when investing in such networks. Although there are many factors influencing the riskiness of an NGA investment project, ${ }^{2}$ OPTA (2008) argues that the main factors that negatively affect an investor's incentives to invest in NGA networks are: (i) the uncertainty about future demand for new fiber-based services; and (ii) the regulatory uncertainty related to the regulator's limited ability to make ex-ante credible commitments. The first type of uncertainty includes the uncertainty about: (i) the penetration of the customer base; (ii) the market shares of the investor and the access seekers; and (iii) the consumers' willingness-to-pay for the new fiber-based services. Concerning the second type of uncertainty, regulatory risk could be eliminated if the regulator fixes the principles of tariff regulation for the whole period of the economic lifecycle of an NGA investment. However, regulatory certainty bears the risk of erroneous intervention. According to WIK (2009), it is socially not optimal for the regulator to make ex-ante commitments for an unreasonably long regulatory period. Therefore, in providing greater regulatory certainty the regulator has to make another trade-off between the positive effects of greater certainty on investment incentives and possible negative effects of erroneous intervention on welfare (OPTA, 2010).

The main conclusion is that regulators should provide the investors with significant incentives to invest in NGA networks without distorting competition. The EC issued a Recommendation on regulated access to NGA (EC, 2010b) providing the NRAs with guidelines for tackling the trade-off between fostering competition and promoting investments with regard to NGA. In particular, the aim of this Recommendation is "to foster the development of the single market by enhancing legal certainty and promoting investment, competition and innovation in the market for broadband services in particular in the transition to next generation access networks".

According to the Recommendation, where an investor operator with Significant Market Power (SMP) is found within Market 4 (market for wholesale network infrastructure access) and/or Market 5 (wholesale broadband access), an appropriate set of remedies should be applied. In particular, the EC recommends calculating the access in a cost-based form that incorporates a risk premium. This premium should reflect any additional and quantifiable investment risk

\footnotetext{
${ }^{2}$ For an extensive review of all the factors influencing the riskiness of an NGA investment project, see ERG (2009), pp. 17-18; WIK (2009), pp. 1-7; and EC (2010b), p. 18. 
incurred by the investor. Additional mechanisms serving to allocate the investment risk between investors and access seekers and to foster market penetration, such as ex-ante and ex-post contracts, could also be used. ${ }^{3}$ In such cases, the risk premium is reduced accordingly.

It can thus be deduced that the initial goal of the current regulatory policy in Europe is to promote service-based competition over fiber networks. Given that the prospective investors in NGA networks (and probably the SMP operators) are for large part the former incumbent operators (OPTA, 2010; WIK, 2009), the regulatory goal is to provide the incumbents with significant incentives to invest in new fiber-based access networks and foster competition in the retail market. Although the EC argues that the incorporation of a risk premium into the access pricing formula can promote both investments and competition. Nitsche and Wiethaus (2011) support that a risk premium removes the structural disadvantages of investing only when the NGA investment turns to be successful. Otherwise, the incumbent has to bear all the cost alone since the risk premium does not have any impact on the incumbent's revenues.

In fact, when the incumbent makes an investment in an NGA network it gives up its option to wait to see how uncertainty about markets, costs, and regulations is resolved since network investments are largely irreversible (Pindyck, 2007). This "real option" is analogous to a financial "call option" in the sense that the incumbent has the right but not the obligation to invest in an asset at some future time of its choosing. Therefore, such lost option value reflects an opportunity cost that must be included as part of the cost of the investment (Dixit \& Pindyck, 1994). Alleman, Madden, and Kim (2008) provide an excellent summary of the literature that focuses on the application of real options methodology to the ICT industries and conclude that the magnitude of the option value is directly related to the level of uncertainty of future market conditions. As a result, any additional and quantifiable investment risk incurred by the investor reflects an option value which is translated to a higher risk premium over the cost-based access price. ${ }^{4}$

This view is also expressed by the European Telecommunications Network Operators' Association (ETNO), which comprises most of the European incumbents. It states that even if the probability of success is relatively high, the risk premium proposed by the EC Recommendation does not reflect the structural cost advantage of the second-movers (or, the access seekers) over the investors (ETNO, 2008). Firstly, the second mover can choose between a fixed and a variable cost structure when facing demand uncertainty, heterogeneity, geographical differences and demand evolving over time. This option is widely known as "make-or-buy". Secondly, the access seeker can exit the market at low cost (before making its own investment), whereas the investment of the first mover is typically sunk. Thirdly, the second mover has the option to enter the market once the critical mass has been created. This option is known as "wait-and-see". In addition, even if a risk premium results in higher wholesale revenues for the investor, raising prices for the new infrastructure may lead to a competitive disadvantage of NGA networks vis-à-vis competing platforms and the existing copper network that often will coexist with NGAs for some time. Therefore, ETNO concludes that the proposed risk premium will not solve the lack of incentives for widespread NGA roll-out in Europe unless it incorporates the incumbents' opportunity cost of giving up their "real option".

It is obvious that there is high ambiguity about the effectiveness of a risk premium on encouraging incumbents to invest in NGA networks. This ambiguity is enhanced by the fact that the appropriate array of remedies imposed by an NRA should reflect a proportionate application of the "ladder-of-investment" principle proposed by Cave and Vogelsang (2003). This theory is extensively presented and discussed in Section 3.2 of this paper. Therefore, the ultimate goal of the current regulatory policy in Europe is to encourage the gradual migration from service-based to facilities-based competition over NGA networks.

In conclusion, the analysis of the regulatory economics of NGA investments showed that the optimal regulatory policy should be aligned with the current regulatory framework in the European NGA market described by the following four basic principles concerning:

i) The evolution of the regulatory goals over time. The regulatory policy should initially encourage the incumbent to invest in new fiber-based access networks and promote service-based competition over such networks. Once the new fiber-based access network has been deployed and service-based competition over such networks has been established, the regulatory policy should encourage the access seekers to invest in their own fiber infrastructures.

ii) The characteristics of the access pricing formula. The access to the incumbent's network should be provided at costoriented prices including a risk premium to reflect any additional and quantifiable investment risk incurred by the investor. Risk allocation mechanisms, such as long-term access pricing or volume discounts, which decrease the risk that an investor incurs when investing in NGAs, lead to a respective decrease in the risk premium. However, since the EC Recommendation does not include in such mechanisms the fixed-fee payments, it is deduced that two-part access tariffs do not reflect the current regulatory framework in the European NGA market. Therefore, NRAs should apply uniform (or usage or linear) access prices under a regime of permanent regulation as long as an SMP operator is found within markets 4 and/or 5 .

\footnotetext{
${ }^{3}$ Long-term access pricing and volume discounts are examples of ex-ante and ex-post contracts, respectively. See Inderst and Peitz (2012a) for a discussion about the impact of different contract types on competition and investment incentives.

${ }^{4}$ Franklin and Diallo (2013) propose a model and methodology for valuing the option to delay network investment decisions and calculating costbased access prices by taking into account the fact that an option value multiple must be calculated for each network element where a network element is an identifiable part of the network infrastructure.
} 
iii) The evolution of the access prices. Access prices should be aligned with the EC statement that the appropriate array of remedies imposed by an NRA should reflect a proportionate application of the ladder-of-investment principle.

iv) The provision of regulatory certainty. According to the EC recommendation, regulatory certainty is a key to promoting efficient investments by all operators. Applying a consistent regulatory approach over time is important to give investors confidence for the design of their business plans. In order to mitigate the uncertainty associated with periodical market reviews, NRAs should clarify to the greatest extent possible how foreseeable changes in market circumstances might affect remedies.

\section{Literature review}

In the introductory section, we showed that the permanent regulation of access at uniform cost-based prices, which is designed to stimulate competition in the market by facilitating entry of alternative operators, promotes static efficiency at the cost of dynamic efficiency.

Thus, this section reviews the research articles that shift their focus from the impact of the principles governing the regulation of the copper access networks on static and dynamic efficiency to the deployment of new regulatory approaches that may promote both static and dynamic efficiency (i.e. induce the socially optimal investments in NGA networks). Such alternative approaches depart from existing practices in terms of the access pricing formula and/or the regulatory regime employed. ${ }^{5}$ In the former case the effectiveness of non-uniform or non-cost-based access prices on the levels of competition and investments is studied, whereas in the latter case the impact of non-permanent regulatory regimes on the timing of the investment decisions and on the subsequent competition level is discussed.

The reviewed research articles can be classified into three broad categories as proposed by Vogelsang (2010). The first strand deals with the effect of the regulated access price on the incumbents' incentives to invest in new infrastructures and on the subsequent competition level, independent of the effect on potential alternative competitors. The second strand deals with the incentive effects of unbundling obligations on the entrants' investments and on the subsequent competition level. Last, a third part of the access-related literature deals with incumbent and entrant investment decisions in models that capture a new industry, in which two firms have to decide, which one will invest first and in which access regulation has been established before.

\subsection{Access regulation and an incumbent's incentives to invest}

This section studies the impact of alternative regulatory settings in terms of either the access pricing formula or the regulatory regime employed on the standard trade-off between promoting static and dynamic efficiency.

Klumpp and Su (2010) propose a uniform access price that spreads investment costs over total output quantities (which implies that the incumbent can recoup investment costs through the access prices) in order to show that such an access pricing scheme can promote both static and dynamic efficiency comparing with the monopolistic market (i.e. regulatory holidays). However Nitsche and Wiethaus (2011) show that the result of Klumpp and Su (2010) is dependent on the particular regulatory regime and the assumption about regulatory uncertainty. Thus, they allow the access pricing scheme that spreads investment costs over total output quantities for taking into account different regulatory regimes, as well as, assume that the incumbent invests after the regulator has set the access price (i.e. regulatory certainty). ${ }^{6}$ They show that a regime with fully distributed costs (FDC) ${ }^{7}$ or regulatory holidays induce highest investments, followed by risk-sharing and long run incremental costs (LRIC), which is a particular methodology of forward-looking cost-based regulation. In addition, in combining strong competitive intensity with reasonable investment incentives, simulations indicate that a risk sharing approach induces highest consumer surplus, followed by regimes with fully distributed costs, regulatory holidays and LRIC. Therefore, they conclude that risk-sharing can be an effective tool since it combines relatively high ex-ante investment incentives with strong ex-post competitive intensity. They also confirm that forward-looking cost-based regulation neither induces investments nor consumer surplus.

Contrary to the previous articles that study the impact of different regulatory regimes on the levels of investments and competition Charalampopoulos, Katsianis and Varoutas (2011) and Gavosto, Ponte and Scaglioni (2007) use a real option

\footnotetext{
${ }^{5}$ The following regulatory regimes are studied in the respective literature. Permanent regulation implies that the ex-ante imposed remedies hold for the whole lifecycle of the NGA investment, whereas regulatory forbearance refers to the situation where there is no ex-ante regulation on NGA networks. Regulatory holidays and sunset clauses are intermediate regulatory regimes between regulatory forbearance and permanent regulation. Under regulatory holidays, the investor is not imposed to any regulatory constraints for a predetermined period of time, whereas by imposing a sunset clause, the regulator commits that will withdraw access obligations after a predetermined date.

${ }^{6}$ In a static framework (or in a hypothetical world of economic certainty), the incumbent may invest under regulatory certainty if the investment decision is undertaken after the regulation of the access price. However, the regulation of the access is a dynamic process and regulatory remedies are also imposed after the investment decisions. Although theoretical static models are useful for giving an insight into regulatory policies, we should keep in mind that uncertainty can be reduced to risk, possibly even low risk, but not certainty. This fact is also considered in the EC Recommendation since NRAs are encouraged (in order to provide greater certainty) to clarify to the greatest extent possible (i.e. not to fully commit) how foreseeable changes in market circumstances might affect remedies.

${ }^{7}$ Under the fully distributed costs regulation, the incumbent may recoup NGA investment costs through the access price, regardless of the NGA's market success since the entrant is forced to cover part of the investment costs.
} 
approach in order to study the impact of four different regulatory regimes (permanent regulation, regulatory forbearance, regulatory holidays and sunset clauses) on the timing of the investment decision of an incumbent to expand to a new network infrastructure. The former article shows that regulatory holidays induce the incumbent to expand its current network as soon as the regulatory holiday season ends, which is long before the expiration date of the option to expand. The latter article concludes that investment is carried out immediately under forbearance and regulatory holiday regimes, while it is delayed by around two years in the other cases. Therefore, it can be deduced that both articles argue that regulatory holidays appear superior to the other regulatory regimes, although the two papers provide different results about the impact of regulatory holidays on the particular timing of the investment. In combining these results with those of Nitsche and Wiethaus (2011), it can be deduced that although regulatory holidays appear superior to the other regulatory regimes in terms of both NGA investment level and the timing of the investments, they fail to promote an efficient competition level. In this context Tselekounis, Maniadakis, and Varoutas (2013) show that the regulator should allow the monopolist to geographically price discriminate since such pricing regime results in better investment and welfare outcomes than uniform pricing as long as the investment cost is not extremely low.

Contrary to the aforementioned articles that study the efficiency implications of different regulatory regimes, Tselekounis and Varoutas (in press) study the impact of the uncertainty about future access prices on an incumbent's incentives to undertake the socially optimal investments in NGA networks. For this reason, they assume that the regulator sets the access price at the marginal cost of providing the access with some probability and gives an access markup, which equals the average cost of the investments, with the complementary probability. They found that when the slope of the marginal investment cost function is not particularly steep in relation to the impact of investments on demand, the incumbent underinvests compared to the socially optimal investment level. On the contrary, when the impact of investments on demand is low in relation to the slope of the marginal investment cost function, the incumbent may overinvest or underinvest depending on the probability of incorporating an access markup into the access price. Therefore, uniform access prices may lead to significant welfare losses due to the impact of regulatory uncertainty on investment incentives.

Brito, Pereira and Vareda (2010) study the impact of the regulatory commitment problem on the effectiveness of twopart access tariffs to solve the dynamic consistency problem of the regulation. They find that when the investment cost is low compared to the investment benefits, two-part tariffs solve the dynamic consistency problem either under regulatory certainty or uncertainty. In this case, the optimal regulatory policy is to set the fixed access price in order to induce investments by the incumbent and the usage access price at the marginal cost of providing the access in order to promote static efficiency. If, on the contrary, the investment cost takes intermediate values compared to the investment benefits, the commitment and the no-commitment games have different equilibria, with the incumbent investing in the commitment equilibrium, and not investing in no-commitment game. Last, if the investment cost is high compared to the investment benefits, investment is not socially desirable under both commitment and no-commitment games. Therefore, two-part access tariffs may not solve the dynamic consistency problem even when the regulator can commit ex-ante to a particular access pricing policy.

\subsection{Access regulation and an entrant's incentives to invest}

The second literature strand deals with the impact of access regulation on an entrant's incentives to invest in network upgrade. In particular, this literature studies whether service-based competition serves as a stepping stone to facilitiesbased competition or the presence of the option to "buy" the incumbent's facilities represents an opportunity cost when the entrant chooses to engage in infrastructure competition (i.e. creates the so-called "replacement effect").

Cave and Vogelsang (2003) point out that entrants will typically invest in replicable assets first and then progress to less replicable ones. Thus, they rank the incumbent's network assets according to their degree of replicability from an entrant's perspective and propose an innovative access scheme in which the price for the less replicable network elements is low but increasing over time as assets are replicated. Therefore, as the entrant's customer bases grow, the access price increases in order to encourage the entrant to invest in the next less replicable asset. This process continues until the entrant invests in its own infrastructure which represents the higher rung in the investment ladder. Thus, the so-called "ladder-of-investment" theory argues that service-based competition serves as a stepping stone to facilities-based competition. Cave (2006) proposes and illustrates methods for assessing the replicability of different assets and sets out the steps which regulators can follow in implementing the approach. An alternative regulatory tool that resembles the ladder-of-investment approach is the already discussed "sunset clause" regulatory regime. By imposing a sunset clause, the regulator commits that will withdraw access obligations after a predetermined date. The building block of both approaches is the expectation that as service-based competition becomes less attractive over time, the entrant will gradually invest in its own network infrastructures.

Although sunset clauses and the ladder-of-investment theory have been embraced by many telecommunications regulators and organizations (ARCEP, 2007; EC, 2010b; ERG, 2005, 2006), the related literature provides mixed results about the effectiveness of each approach to make service-based and facilities-based competition complements in promoting both investments and competition. Avenali, Matteucci, and Reverberi (2010) use a dynamic discrete choice model and assume that developing an alternative infrastructure requires both time and an installed base of consumers which implies that a period of service-based competition is a prerequisite for facilities-based competition in the next period. They find that a multi-period schedule where regulated access charges rise over time is critical to foster efficient infrastructure investments, whereas a sunset clause on regulation dilutes investment incentives. In addition, they point out that the regulatory 
commitment problem may affect the robustness of their main result. Thus, they propose that the access price should depend both on time and entry period in order to ensure that late entrants are provided with the same dynamic access conditions. In a more recent paper, Bourreau and Drouard (2010) use a general model of competition in order to study the impact of both a "replacement effect" and a "stepping stone effect" on an entrant's incentives to invest in network upgrade. Thus, they allow an initial serviced-based period for the entrant to build its market share progressively. This implies that the entrant might have significant incentives to prolong the service-based competition phase in order to build a larger market share. They show that if facilities-based entry is a short-term (long-term) possibility, the replacement effect (the stepping stone effect) prevails, and hence, a phase of service-based competition delays (accelerates) facilities-based entry.

Therefore, as Bourreau, Doğan, and Manant (2010) point out, a phase of service-based competition may be a necessary, but not a sufficient, condition to ensure that it will serve as a stepping stone to facilities-based entry if the replacement effect is neutralized. The authors also challenge another assumption of the ladder-of-investment theory which states that the regulator has the instrument to neutralize the replacement effect. They argue that although access prices that increase over time may neutralize the replacement effect, credibility of regulatory commitments and informational requirements raise several concerns about the successful implementation of this theory.

The effectiveness of the ladder-of-investment theory on encouraging new entrant operators to invest in their own access infrastructures has been studied not only theoretically but also empirically. Distaso, Lupi, and Manenti (2009) use semiannual data from 12 European countries (study period: January 2005-July 2007) and test the ladder-of-investment theory by looking at the link between the prices of wholesale access services and the relative growth rates of the three alternative inputs that can be used by new entrants to provide access and broadband services to end users: bitstream services, LLU services and their own networks. Although they point out that the policies adopted by NRAs are broadly consistent with the ladder-of-investment theory, their graphical results reveal that only few countries (France and Spain) have succeeded in encouraging the entrants to climb the investment ladder due to increasing access prices over time. In a more recent empirical study Bacache, Bourreau, and Gaudin (2011) use semi-annual data (from 2002 to 2009) covering incumbent and entrant fixed-broadband operators in 15 European member states in order to test the ladder-of-investment hypothesis. They find no statistically significant effect of the number of unbundled lines on the number of new access infrastructure lines built by entrants, which implies that there is no evidence in support of the ladder-of-investment hypothesis.

\subsection{Access regulation and both firms' incentives to invest}

This strand of the literature on access pricing and investment incentives focuses on the effect of access prices on firms' incentives to invest in new access networks. This implies that the strategic impact of the investment decision of each firm on the other firms' investment decisions is taken into account. In particular, the related articles assume that there are two firms which have to decide if and when to deploy a new access network. It is obvious that this part of the literature does not discriminate between an incumbent and an entrant since either firm can invest first in a new network infrastructure. Thus, both firms are assumed to be symmetric.

In a dynamic context, firms may tend to preempt each other when there are significant first-mover advantages and delay investments when there are significant second-mover advantages. The former case triggers a race for investment, whereas the latter case leads to a waiting equilibrium. The regulator's goal is to set the access price at the level that incentivizes each firm to invest at the socially optimal time.

Hori and Mizuno (2006) use a model with stochastically growing demand in order to assess the impact of a uniform access price on a race of investment between two firms. They find that in the retail market an increase in the access price induces the leader to enter the market earlier and the follower to enter the market with access later or to build its bypass facility earlier. In addition, they also provide the conditions that induce the follower to enter the market by accessing the leader's network and then build its own network. Hori and Mizuno (2008) improve their previous work by comparing the impact of service-based and facilities-based competition on the timing of investments. They show that in service-based competition a follower enters the market earlier and builds a bypass later than in facilities-based competition. Concerning the leader's investment timing, they provide the conditions that determine the priority of the two competition schemes in terms of monopoly rents, access charges and degree of uncertainty.

In a more recent article Vareda and Hoernig (2010) assume two-part access tariffs in which the usage price is used to maximize static efficiency and the fixed price to induce dynamic efficiency (i.e. to incentivize each firm to invest at the socially optimal time). They show that in a waiting equilibrium higher access prices make both firms to invest earlier. Considering the preemption equilibrium, they conclude that higher access prices have also a positive effect on the follower's investment timing but their impact on the leader's investment timing is ambiguous. Therefore, the first-best cannot be achieved with any given two-part access tariff. Thus, a sunset clause (respectively, a regulatory holiday) may lead to the first-best investment outcome if the follower's private investment incentives are small (respectively, high).

\subsection{Discussion}

This section reviewed the articles that propose new regulatory approaches and then assess their effectiveness and efficiency implications. There are many useful regulatory implications that can be drawn by the analysis of the effect of the proposed approaches on firms' incentives to invest in NGA networks, as well as, on the subsequent competition level. 
Firstly, although a regulatory holidays regime seems to induce the incumbent to deploy a broader NGA network earlier, it is inferior to risk-sharing and FDC regimes in terms of consumer surplus. However, regulatory holidays are superior to LRIC in terms of both investments and competition. In addition, a departure from uniform access prices cannot solve the dynamic consistency problem unless the investment cost is low compared to the investment benefits. Therefore, a departure from the permanent regulation of access at uniform cost-based prices is not adequate to promote both competition and investments in NGA networks by the incumbents. Secondly, although a phase of service-based competition may be a necessary, but not a sufficient, condition to ensure that it will serve as a stepping stone to facilities-based entry, an access price that increases over time does not always succeed in encouraging the entrants to climb the investment ladder.

It can thus be deduced that the related literature on the relationship between access regulation and investment incentives does not provide an optimal access pricing policy that promotes competition and encourages investments in NGA networks by incumbents and then entrants. In particular, the above results raise serious doubts about the effectiveness of the EC Recommendation concerning the permanent regulation of access at uniform cost-based prices and the implementation of the ladder-of-investment theory during the migration to a phase of facilities-based competition. However, the research articles study the impact of alternative regulatory approaches on either the incumbents' or the entrants' investment incentives without considering the strategic interaction between their investment decisions. On the contrary, the current regulatory framework in the European NGA market considers that the incumbent will invest first in new access infrastructures, while the entrants will gradually invest in their own bypass facilities. It is obvious that when the incumbent (respectively, the entrant) decides its optimal investment decision, it takes into account the optimal investment decision of the entrant (respectively, the incumbent). This implies that the disclosed access pricing policy should take into account the impact of access regulation on both firms' incentives to invest although such investment decisions are taken in a sequential order. The third literature strand takes into account such strategic reaction by allowing either an incumbent or an entrant to invest first in NGA networks. However, it provides mixed results concerning the impact of access prices on the leader's investment incentives even if a two-part access price is used to maximize both static and dynamic efficiency, as well as, it does not discriminate between a vertically integrated incumbent and a new entrant operator.

To best of authors' knowledge, the only paper that reflects the current regulatory framework in terms of the evolution of the regulatory goals over time is Vareda (2011). In particular, it considers a dynamic framework in which an incumbent chooses how much to upgrade the quality of its network and then an entrant, at each point in time, has the option to enter as a service-based competitor, by asking for access to the incumbent's network, or as a facilities-based competitor, by building a bypass network. He shows that when the regulator can ex-ante commit to a two-part access tariff: (i) the entrant's investment in a bypass network is delayed with a higher incumbent's investment in quality; (ii) the possibility of investment in a bypass network by the entrant has a positive effect on the incumbent's incentive to upgrade quality; (iii) the effect of access prices on both incumbent and entrant firms' incentives to invest is ambiguous; and (iv) a welfare improving access tariff that could be designed by the regulator would be one where the access fee is increasing (decreasing) in quality if the incumbent's incentives are such that it under-invests (over-invests).

However, the work of Vareda (2011) not only uses a two-part access tariff (rather than a uniform access price), but also assumes that the access price is fixed over time (rather than reflecting a proportionate application of the ladder-ofinvestment principle). Therefore, his model fails to align with two of the four basic principles of the EC Recommendation.

On the contrary, this paper proposes an innovative approach that reflects the current regulatory framework in the European NGA market as described by the EC Recommendation (EC, 2010b). In particular, the proposed approach models the four basic principles of the current European regulatory framework and then assesses its effectiveness on inducing facilitiesbased competition over NGA networks. This implies that this paper can be included in the literature that departs from assessing the efficiency outcomes of the regulation of the copper access networks. It is shown that the proposed approach meets the current regulatory goals since it tackles the initial trade-off between encouraging the incumbents to invest in NGA networks and fostering competition, while it incentivizes the entrants to gradually climb the ladder-of-investment when the NGA investment is proven to be successful. Therefore, the proposed approach not only fills the gap between the reviewed literature and the current European regulatory framework, but also provides an effective migration path towards facilitiesbased competition over NGA networks.

\section{A CDS approach}

This section presents an innovative approach that aims to reflect the current regulatory framework in the European NGA market and then to assess its effectiveness on promoting competition and encouraging investments in NGA networks by both incumbents and entrants. In particular, the proposed approach is based on the basic principles governing a Credit Default Swap (CDS). Thus, this section initially provides a brief review of the basic features of a typical CDS contract. Then, it presents the proposed method, describes its implementation and discusses its impact on investment incentives and competition. It is shown that the proposed approach represents an effective way towards facilities-based competition over NGA networks.

\subsection{Background}

A CDS contract is an agreement between two parties, the protection buyer and the protection seller. The first party to the contract, the protection buyer, wishes to insure himself against the possibility of default on a bond issued by a particular 
company. The company that has issued the bond is called the reference entity. The second party to the contract, the protection seller, is willing to bear the risk associated with default by the reference entity. The protection buyer of the CDS makes a series of payments (the CDS "premium" or "spread") to the protection seller and, in exchange, receives a payoff in the event of a default by the reference entity. If a default does not occur over the life of the contract, the contract expires at its maturity date, and hence, the protection seller does not make any payments to the protection buyer. ${ }^{8}$

The next section shows how the basic logic of a typical CDS contract can be applied in the telecommunications markets in order to induce facilities-based competition over new fiber access networks.

\subsection{The model}

The proposed model assumes that there are two parties in the contract: the incumbent, which invests in NGA networks, and the regulator. They both agree on a business plan that allows the incumbent to recover ${ }^{9}$ the investment in a nationwide NGA deployment (i.e. the deployment of an NGA network in every geographic area of the country) during a certain period of time. If the investment has not been recovered at the end of this period, the regulator commits itself that it will compensate the incumbent for the unrecovered part of the investment. After the end of this period, no regulatory remedies will be imposed to the incumbent (sunset clause). In exchange, the incumbent should make periodic payments to the regulator. However, the regulator chooses to subtract this amount from the payments that an access seeker makes to the incumbent in order to have an access to the NGA networks. This implies that the incumbent does not pay a periodic premium to the regulator but it subtracts this amount from the access payments it receives. If, however, the investment has been recovered before the end of the clause, the regulator does not make any payment to the incumbent, the incumbent stops making indirect periodic payments to the access seeker and no remedies imposed to the incumbent. In such contract, the incumbent is the protection buyer and the regulator is the protection seller which will compensate the incumbent in the case of a default event (i.e. if the investment has not been recovered at the end of the predetermined period).

A very significant issue that should be further investigated is the content of the business plan. In particular, the incumbent and the regulator agree on a business plan that describes the time evolution of the basic parameters affecting the profitability of an NGA investment project. In other words, the business plan should assess the period of time required for the recovery of the investment under plausible assumptions about the main factors that affect the profitability of an investment in NGA networks. As it has already been stated above, the main factor that negatively affects the investment incentives in NGA networks is the uncertainty about the demand parameters, such as the diffusion of the new fiber-based services, the consumers' willingness-topay for such services and the market shares of the incumbent and the entrant. Thus, the business plan should clearly state how these parameters will evolve over time.

It is expected that the diffusion process will follow an S-shaped curve since the most known models used for such purposes provide an S-shaped curve describing technology diffusion among specific populations (Michalakelis, Varoutas, \& Sphicopoulos, 2008). At the initial stages of the diffusion process the potential buyers of the new product are the innovators and then the early adopters. Internal influences, such as word-of-mouth, and external influences, such as mass-media communication, facilitate the adoption of the new product by early majority, late majority and, finally, laggards. Therefore, the S-shaped curve reflects the fact that the migration from copper access networks to NGA networks is a slow process (Bourreau, Cambini, \& Hoernig, 2012).

However, according to Moore (1991) the most important phase in the diffusion process is the transition from the early adopters to early majority. The reason is that there are qualitative differences between these two groups, and hence, early adopters do not make good references for the early majority. Therefore, the whole investment may fail if the diffusion process does not cross this chasm. It is thus expected that the entrant will exploit the second-mover advantage of "waitand-see" until the diffusion process cross this chasm. This implies that at the initial stages of the diffusion process the incumbent will serve almost the whole market. Hence, the incumbent takes the more interesting part of the market first and it becomes more difficult or costly (i.e. increases the switching cost) for the entrant to reach the market share needed for its profitability (WIK, 2009). This implies that if the diffusion process crosses this chasm, the entrant increases its market share but this increase is mainly due to new consumers rather than existing ones.

It is thus obvious that even if fiber access networks replace much of the existing copper access infrastructures, there will be a period during which both are in operation and are competing for customers. This implies that low access prices for the copper access networks increase the opportunity cost of the entrant's investment in NGA networks, making such investment less attractive, whereas low retail prices for the copper-based services discourage consumers to move from the old to the new technology unless the fiber-based services are priced sufficiently low as well (Bourreau, Cambini, \& Dogan, 2012). The former effect is widely known as a "replacement effect" and the latter as a "business migration" effect. The fundamental point is that higher access prices lead to higher retail prices. Therefore, a higher difference between fiber

\footnotetext{
${ }^{8}$ For a detailed description of CDS contracts, see Longstaff, Mithal, and Neis (2005) and Arora, Gandhi, and Longstaff (2012).

9 The exact interpretation of the term "investment recovery" depends on the particular financial methodology mutually agreed by the incumbent and the regulator in order to define the terms of the contract. Our main thesis is that this is an economic rather than an accounting term, and therefore, it is disconnected from any accounting terms (e.g. depreciation). We expect that the "investment recovery" will be based on discounted cash flows analysis (e.g. payback period based on discounted cash flows) with a fixed time horizon. Further discussion on the matter is beyond the scope of this paper, although we acknowledge that it provides an excellent field for future research.
} 
and copper access prices implies a higher difference between fiber and copper retail prices, which in turn, disincentivizes both entrant and consumers to move to the NGA networks. As a result, the relationship between the fiber and the copper access prices not only affects the providers' profits and investment incentives, but also the diffusion process of the new technology. ${ }^{10}$

Another significant source of uncertainty is related to the regulator's limited ability to make ex-ante credible commitments. However, this model proposes that the contract commits the regulator to apply a certain policy during the whole predetermined period. This policy, which concerns the derivation of the access pricing formula, as well as, its evolution over time, is known to the incumbent ex-ante. As it has already been stated above, it is not optimal for the regulator to intervene in the market very often because it dilutes investment incentives. On the contrary, it is socially not optimal for the regulator to make ex-ante commitments for an unreasonably long regulatory period. Thus, this model proposes an intermediate solution in which the regulator makes periodic reviews at a predetermined period. In each periodic review the regulator may increase or decrease the access price according to certain rules that are described in the contract and presented in the following section. It can thus be deduced that the incumbent invests in NGA networks under regulatory certainty.

\subsection{Implementation}

At time $t=0$ the incumbent and the regulator agree on a business plan that allows the former to have recovered the investment in NGA networks at time $t=T$ with a given probability. Or, in other words, they estimate the probability of default $\left(P_{0}\right)$, as well as, the corresponding unrecovered part of the investment $\left(X_{0}\right)$ at the end of the predetermined period. The subscript " 0 " denotes the values of the parameters $P_{t}$ and $X_{t}, t \in[0, T]$, at the time that the estimation takes place (i.e. $t=0$ in this case). Based on the estimated values of $X_{0}$ and $P_{0}$, they assess the amount of the periodic payments $\left(K_{0}\right)$ that the incumbent should make to the regulator. This implies that if the estimated demand parameters at $t=0$ coincide with the actual ones during the whole predetermined period $T$, the total amount of the periodic payments will be $T K_{0}{ }^{11}$ However, the regulator chooses not to receive such payments but to subtract this amount from the access payments. Therefore, the reduced access payments that the entrant will finally make to the incumbent from $t=0$ to $t=T$ are given by:

$$
A P_{0-T}=W_{C} \sum_{t=0}^{t=T} Q_{t}^{E}-T K_{0}
$$

or,

$$
A P_{0-T}=\left(W_{C}-R_{0}\right) \sum_{t=0}^{t=T} Q_{t}^{E}
$$

where $W_{C}$ denotes the cost-based access price, $Q_{t}^{E}$ represents the estimated number of consumers served by the entrant at time $t, t \in[0, T]$, and $R_{0}$ is a regulatory parameter such that

$$
R_{0} \sum_{t=0}^{t=T} Q_{t}^{E}=T K_{0}
$$

Therefore, the access price that the entrant pays to the incumbent during the $T$ years is given by $W_{0}=\left(W_{C}-R_{0}\right)$. It is thus obvious that the access payments that an entrant pays to the incumbent for one period $t \in[0, T]$ are derived by multiplying the access price with the number of the entrant's subscriber at period $t$. The sum of these payments from $t=0$ to $t=T$ yields the total access payments that the entrant pays to the incumbent in order to have access to the NGA networks for the whole predetermined period $T$. If the estimated demand parameters at $t=0$ coincide with the actual ones during the whole predetermined period $T$, then the initial regulatory policy will lead to the recovery of the NGA investment at time $t=T$. Since the main factor that affects the profitability of an NGA investment is the demand for the new fiber-based services, it is expected that the cumulative recovery of the investment will also follow an S-shaped pattern as depicted in Fig. 1.

However, since the periodic payments are closely related to the possibility of default, it can be deduced that the amount of such payments may vary over time. The reason is that although the business plan forecasts the evolution of the demand parameters over time, it is uncertain whether the actual demand will coincide with the estimated one. For example, even if the diffusion process will follow an S-shaped curve, the time at which the saturation level will be achieved may deviate from the estimated one. As a result, it is also uncertain whether the investment will have been recovered at the end of the predetermined period. Since it is not optimal for the regulator to make ex-ante commitments for unreasonably short or long regulatory periods, the proposed approach states that the regulator makes periodic reviews at predetermined periods in

\footnotetext{
10 See Bourreau, Cambini, and Doğan (2013), Bourreau, Lupi, and Manenti (2013), Brito, Pereira, and Vareda (2012), Cambini and Silvestri (2012), Cave, Fournier, and Shutova (2012), Inderst and Peitz (2012b), and Neumann and Vogelsang (in press) for a discussion about the impact of the regulation of the legacy network on the firms' investment incentives when the NGA market is left unregulated or when there is an interplay between the access prices of the two networks.

11 In fact, $X_{0}$ denotes the estimation at $t=0$ for the discounted unrecovered part of the investment, and hence, the estimation at $t=0$ for the total amount of the discounted periodic payments is given by: $\sum_{t=0}^{t=T} K_{0} /(1+r)^{t}$, where $r$ denotes the interest rate. However, throughout this paper, we have assumed, for simplicity, that $r=0$ since the abstraction of the time-value-of-money does not change the results qualitatively.
} 


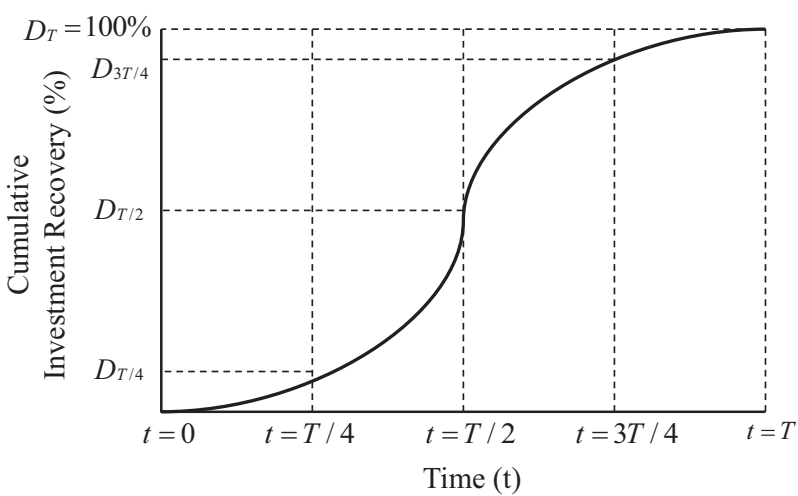

Fig. 1. Cumulative recovery of the NGA investment.

order to correct potential distortions due to any deviation from the estimated parameters. Thus, the business plan clearly states that the regulator will make periodic reviews every $T / m$ years. In the example presented in Fig. 1, the regulator makes periodic reviews every $T / 4$ years. In addition, the proposed model states that in each review, the regulator changes the access price only if the initial estimation (made at $t=0$ ) for the cumulative recovery at the time of the review, $D_{t}$, deviates from the actual cumulative recovery more than $x \%$. The exact percentage of $x$ is mutually agreed by the incumbent and the regulator.

However, the most significant issue is how the regulator changes the access price in each periodic review. The reason is that a marginal change in the access price will significantly affect the incumbent's profits, the entrant's investment incentives, as well as, the competition level. The basic principle governing the change in the access price is the estimation of the periodic payments made from the protection buyer to the protection seller in a CDS contract. In each periodic review, the regulator should examine whether the cumulative recovery of the NGA investment is higher or lower than the initially estimated one by more than $x \%$. Therefore, three cases should be studied. In the first case, the investment is successful since the actual cumulative recovery is higher than the initially estimated one by more than $x \%$ (upside case). In the second case, the investment is not successful since the actual cumulative recovery is lower than the initially estimated one by more than $x \%$ (downside case). In the last case, the difference between the actual and the initially estimated cumulative recovery is less than $x \%$ (base case).

\subsubsection{The upside case}

Let's assume that in the first regulatory review $(t=T / 4)$ the actual cumulative recovery is higher than the initially estimated one $\left(D_{T / 4}\right)$ by more than $x \%$, i.e. $\left(D_{T / 4}^{\text {actual }}-D_{T / 4}\right) / D_{T / 4}>x \%$. Therefore, the regulator should intervene in the access market in order to review the access price. In this case, the probability of default decreases since it is more probable that the investment will have been recovered before the end of the predetermined period $T$. Hence, the value of the probability of default at $t=T / 4$ is lower than its value at $t=0$ (i.e. $P_{T / 4}<P_{0}$ ). In addition, the estimated unrecovered part of the investment $\left(X_{T / 4}\right)$ is also lower than the initially estimated one $\left(X_{0}\right)$. As a result, the periodic payments that the incumbent will make to the regulator from $t=T / 4$ until $t=T$ should be lower than the initially estimated ones (i.e. $K_{T / 4}<K_{0}$ ). Thus, the regulator should set $R_{T / 4}$ at the level that makes the following equation hold:

$$
R_{T / 4} \sum_{t=T / 4}^{t=T} Q_{t}^{E}=(T-T / 4) K_{T / 4}
$$

In other words, the regulator should assess the value of $R_{T / 4}$ that leads the left side of Eq. (4) to decrease as much as the decrease caused by the upside case to the right side of Eq. (4). Firstly, note that a decrease in the regulatory parameter $R_{t}$ leads to an increase in the access price. Indeed, the access price that the entrant will pay to the incumbent from $t=T / 4$ until $t=T$ is given by $W_{T / 4}=\left(W_{C}-R_{T / 4}\right)$. Obviously, this access price is higher than $W_{0}$ since $R_{T / 4}<R_{0}$. A higher access price causes the entrant's market share to decrease and the incumbent's market share to increase. Secondly, a higher access price leads to a higher retail price for the fiber-based services. Therefore, the difference between the retail prices of the copper and the NGA networks increases, thereby making the latter less attractive for consumers. This result mitigates the diffusion process and negatively affects the demand faced by each provider. It is thus obvious that when the regulator decreases the regulatory parameter $R_{t}$, the entrant's consumer base decreases due to the aforementioned reasons. ${ }^{12}$ Therefore, a proper

\footnotetext{
${ }^{12}$ The value of $x$ should be high enough in order to ensure that the annual periodic payments which the incumbent will make to the regulator ( $K_{t}$ ) are substantially decreased (or increased in the downside case). The reason is that if the decrease in the entrant's consumer base is much higher than the decrease in the annual periodic payments, then a higher $R_{t}$ may be required in order to make Eq. (4) hold. However, this is in contrast with the fact that the decrease in the entrant's consumer base stems from a decrease in $R_{t}$. It is thus obvious that the access price should be reviewed when the actual diffusion is significantly deviated from the initially estimated one (i.e. either in upside or downside cases).
} 
decrease in $R_{t}$ ensures that the decrease in the amount subtracted from the access payments (left side of Eq. (4)) is equal to the decrease in the amount that the incumbent should have paid to the regulator (right side of Eq. (4)). ${ }^{13}$

The most interesting result of this regulatory policy is that it encourages the entrant to invest in its own facilities. Indeed, an increase in the access price of the NGA networks raises the entrant's variable cost, decreases its market share and its profits, and hence, makes fiber unbundling less attractive for the entrant. In conclusion, the proposed approach provides the entrant with incentives to climb the ladder-of-investment in each upside case. As the entrant gradually invests in its own network, it becomes more effective competitor. As a result, the retail price decreases which, in turn, enhances the diffusion process. Therefore, this approach increases the probability of a successive upside case in the next regulatory review. It is obvious that this approach will be implemented as long as the actual cumulative diffusion is higher than the initially estimated ones (i.e. $D_{T / 4}, D_{T / 2}, D_{3 T / 4}$ ) by more than $x \%$.

The opponents of this approach may argue that the incumbent does not have any incentives to invest under such a regulatory approach since its profits stoke the recovery of the investment, whereas the entrant makes positive profits by exploiting the second-mover advantages. However, we should keep in mind that as soon as the investment has been recovered, the sunset clause ends. Therefore, the incumbent pursues to accelerate the diffusion process in order to recover the investment earlier and then reap the benefits of being the first-mover (i.e. its high market share consisting of consumers with high willingness-to-pay).

\subsubsection{The downside case}

Now, let's discuss the case of a downside. Assume, for example, that the actual cumulative recovery is lower than the estimated one $\left(D_{T / 4}\right)$ by more than $x \%$, i.e. $\left(D_{T / 4}-D_{T / 4}^{a c t u a l}\right) / D_{T / 4}>x \%$. Therefore, the regulator should review the access price. In this case the estimation made at $t=T / 4$ for the probability of default, as well as, for the unrecovered part of the investment are higher than the initially estimated ones. Hence, $P_{T / 4}>P_{0}$ and $X_{T / 4}>X_{0}$. As a result, the periodic payments that the incumbent will make to the regulator from $t=T / 4$ until $t=T$ should be higher than the initially estimated ones (i.e. $K_{T / 4}>K_{0}$ ). Contrary to the upside case, the regulatory policy that makes Eq. (4) hold is to increase the regulatory parameter $R_{t}$.

The reason is that an increase in $R_{t}$ has a twofold impact on the entrant's consumer base. Firstly, the access price decreases, and hence, the entrant's market share increases. Indeed, the access price that the entrant will pay to the incumbent from $t=T / 4$ until $t=T$ is given by $W_{T / 4}=\left(W_{C}-R_{T / 4}\right)$ and is lower than $W_{0}$ since $R_{T / 4}>R_{0}$. Secondly, a lower access price for the NGA networks leads to a lower retail price for the fiber-based services. Therefore, the difference between the retail prices of the copper and the NGA networks decreases, thereby making the latter more attractive for consumers. This result positively affects the demand faced by each provider and enhances the diffusion process. Therefore, an increase in the regulatory parameter $R_{t}$ leads the entrant's consumer base to increase. As a result, a proper increase in $R_{t}$ ensures that the increase in the amount of the left side of Eq. (4) is equal to the increase in the amount that the incumbent should have paid to the regulator given by the right side of Eq. (4).

Of course, since the access price decreases, the entrant does not have any incentives to invest in its own facilities. However, in this case, the regulator's goal is to increase the total demand rather than incentivizing the entrant to invest in NGA networks. The reason is that the entrant invests in NGA networks only when the NGA investment is successful. Therefore, the regulator should first promote the success of the NGA investment and then encourage the entrant to invest in its own facilities. It is obvious that the proposed approach fulfills in enhancing the diffusion process since a lower access price facilitates service-based competition over NGA networks, as well as, the new access network becomes more attractive for consumers. Therefore, it is expected that in the next regulatory review the diffusion process (and by extension the cumulative recovery) will coincide with the initially estimated one.

The opponents of the proposed approach may also argue that a lower access price decreases the incumbent's profits. Therefore, the incumbent would not have signed the modified CDS contract. However, recall that the probability of a downside is higher at the initial stages of the diffusion process and that the incumbent's goal is to recover the NGA investment as soon as possible in order to exploit the first-mover advantages and maximize its profits after the end of the sunset clause. This implies that the incumbent is willing to sacrifice some short-run profits for maximizing its long-run profits. A basic prerequisite for the early recovery of the NGA investment is the acceleration of the diffusion process and especially the crossing of the chasm at its initial stages. In addition, high access prices are more profitable for the incumbent in the upside case (i.e. when the entrant has a significant market share). On the contrary, in the downside case, a high access price deteriorates the entrant's position in the market, thus making the magnitude of such an access price insignificant and the success of the NGA investment more uncertain.

However, it should be noted that in the downside cases the proposed approach is more effective at the initial stages of the diffusion process rather than at its final stages. The reason is that the potential increase in the adoption rate due to a decrease in the access price is limited as the diffusion process approaches its saturation level. However, it is expected that

${ }^{13}$ Of course, an increase in the regulatory parameter $R_{t}$ causes the opposite results. In this case, the left side of Eq. (4) is higher than the respective right side, which implies that such a regulatory decision does not reflect the reduction (due to the upside case) in the amount that the incumbent should have paid to the regulator. 
the proposed model can handle the high probability of a downside at the initial stages of the diffusion process by increasing the adoption rate, and hence, leading to an upside at the following regulatory reviews.

\subsubsection{The base case}

In the base case, the difference between the actual cumulative recovery and the initially estimated one is lower than $x \%$, i.e. $\left|D_{T / 4}-D_{T / 4}^{\text {actual }}\right| / D_{T / 4}<\chi \%$. This implies that the initially estimated demand parameters are very close to the actual ones, and hence, the actual diffusion process is almost as expected. Therefore, the regulator does not change the access price until the next regulatory review.

\subsubsection{A numerical example}

This section presents a numerical example of the implementation of the CDS approach in order to show its impact on competition and investment incentives under an upside, a downside and a base case. In addition, it presents the competition and investment outcomes when the NGA investment is recovered before, after and at the predetermined period.

Assume a hypothetical country of 10 million citizens. The regulator and the incumbent agree on a business plan which forecasts the diffusion process of the new fiber-based services for the next 12 years. The diffusion process follows the S-shaped pattern of Fig. 1 and approaches its saturation level of 50\% in the 12 th year. In addition, the cumulative recovery at $t \in[0, T]$ is assumed to be twice the diffusion of the fiber-based services at time $t$. Therefore, the cumulative recovery follows an S-shaped pattern as depicted in Fig. 2.

It is further assumed that the incumbent's initial market share of $95 \%$ decreases by $5 \%$ each year. Based on these estimations, the regulator and the incumbent agree that the NGA investment level will have been fully recovered after $T=12$ years with a certain probability. Table 1 presents the estimated annual cumulative recovery (\%), as well as, the modified estimations made in $t=3$ and $t=6$ due to a downside and an upside case, respectively.

However, if the NGA investment has not been recovered after 12 years, the regulator will pay to the incumbent the unrecovered part of the investment. The investment cost of a nationwide NGA deployment is assumed to amount to $F=10^{10} €$.

The initial estimation for the unrecovered part of the investment $\left(X_{0}\right)$ and the probability of default $\left(P_{0}\right)$ leads to an initial estimation of the annual periodic payments, e.g. $K_{0}=5 \times 10^{6} €$. This implies that if the initial assumptions coincide with the actual ones during the whole regulatory period, the investment will have been recovered after 12 years, whereas the incumbent will have paid to the regulator $T K_{0}=60 \times 10^{6} €$. As it has been already mentioned above, the regulator does not receive this amount, but he subtracts it from the cost-based access payments. The cost-based access price is given by $W_{C}=c(1+W A C C)$, where $c$ represents the cost of providing the access to the NGA networks and WACC is the weighted average cost of capital of the incumbent. This implies that if $c=10 €$ and $W A C C=10 \%$, the cost-based access price is $11 €$. In addition, the value of $R_{0}$ that makes Eq. (3) hold is 5.358€ since $\sum_{t=0}^{t=12} Q_{t}^{E}=11,197,044$. Therefore, the access price is $11-5.358=5.642 €$. According to Eq. (2), the total access payments are $63,173,722 €$.

However, the regulator should review the access price every 3 years in order to ensure that the diffusion process and the subsequent cumulative recovery will result in the recovery of the NGA investment after 12 years. If the difference between the actual cumulative recovery and the initially estimated one is more than $x=10 \%$, then the regulator changes the access price.

Let's assume that the time lag of the diffusion process is one year, which implies that in the first regulatory review $(t=3)$ the cumulative recovery is $6 \%$ and the saturation level in $t=12$ will be $96 \%$. In this case, $x>10 \%$, and hence, the regulator should change the access price. The reason is that in the downside case the periodic payments that the incumbent should make to the regulator increase. Assume, for example, that $K_{3}=8 \times 10^{6} €$, which implies that $(T-3) K_{3}=72 \times 10^{6} €$.

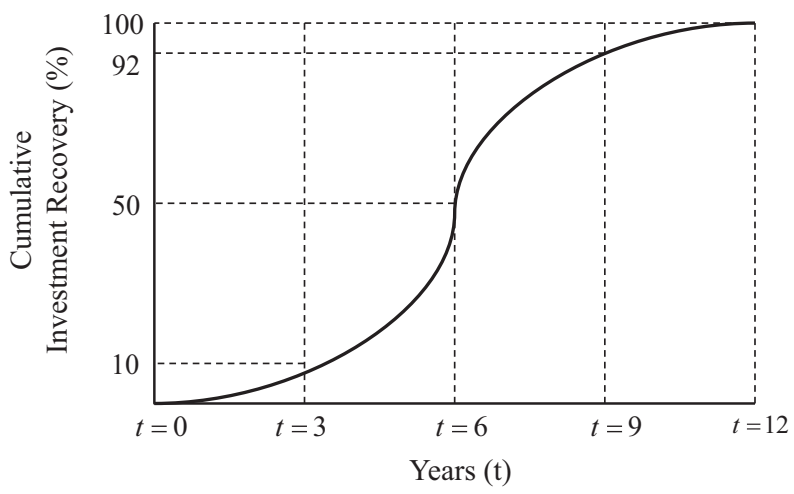

Fig. 2. Example of the cumulative recovery of the NGA investment. 
Table 1. Estimated and actual cumulative recovery

\begin{tabular}{rcc}
\hline Year $(\boldsymbol{t})$ & $\begin{array}{l}\text { Initially (made at } \boldsymbol{t}=\mathbf{0} \text { ) estimated } \\
\text { cumulative recovery }\end{array}$ & $\begin{array}{l}\text { Modified estimated } \\
\text { cumulative recovery made at } \boldsymbol{t}=\mathbf{3}\end{array}$ \\
\hline 0 & 0 & $0^{\mathrm{a}}$ \\
1 & 2 & $2^{\mathrm{a}}$ \\
$\mathbf{c u m u l a t i v e}$ recovery made at $\boldsymbol{t}=\mathbf{6}$
\end{tabular}

${ }^{\text {a }}$ Indicates the actual cumulative recovery at $t \in[0, T]$.

Therefore, the regulator should increase the regulatory parameter $R_{t}$ such that the product of $R_{3}$ and the subsequent increased consumer base of the entrant is equal to $(T-3) K_{3}$. Hence, the incumbent's market share decreases with a higher rate, e.g. 7\% each year. In addition, the decrease in the access price results in a decrease in the retail price of the fiber-based services which, in turn, enhances the diffusion process. It is thus expected that in the next regulatory reviews the actual penetration levels will coincide with the initially estimated ones. This implies that the cumulative entrant's subscribers from $t=4$ to $t=12$ are $13,359,117$, and hence, the value of $R_{3}$ that makes Eq. (4) hold is $R_{3}=5.389$. In this case, the access price is $W_{3}=11-5.389=5.611$.

Now, let's examine an upside case. Assume that in the next regulatory review $(t=6)$ the cumulative recovery is $66 \%$, and hence, the NGA investment will have been recovered at $t=11$. As a result, $x>10 \%$ which implies that the regulator should change the access price. The reason is that in the upside case the annual periodic payments that the incumbent should make to the regulator decrease. Assume, for example, that $K_{6}=3 \times 10^{6} €$, which implies that $(11-6) K_{6}=15 \times 10^{6} €$. Therefore, the regulator should decrease the regulatory parameter $R_{t}$ such that the product of $R_{6}$ and the subsequent decreased consumer base of the entrant is equal to $(T-6) K_{6}$. A decrease in $R_{t}$ has a twofold effect on the entrant's consumer base. Firstly, the access price increases which, in turn, leads the entrant's market share to increase with a lower rate (or, equivalently, the incumbent's market share decreases with a lower rate, for example 3\%). Secondly, the increase in the access price results in an increase in the retail price of the fiber-based services which, in turn, negatively affects the diffusion process. It is thus expected that in the next regulatory reviews the actual penetration levels will coincide with the initially estimated ones and the investment will have been recovered at $t=12$. Therefore, the cumulative entrant's subscribers from $t=7$ to $t=12$ are 9,995,395, and hence, the value of $R_{6}$ that makes Eq. (4) hold is $R_{6}=1.507$. In this case, the access price is $W_{6}=11-1.507=9.493$.

It seems that the proposed approach hinders the diffusion process by increasing the retail price through the increase in the access price. However, the increase in the access price, as well as, the decrease in the entrant's market share will probably cause the entrant to climb the investment ladder. This expectation is enhanced by the fact that there was an upside in the diffusion process, which triggers the regulatory intervention in the access market, and hence, the investment seems to be profitable. As the entrant gradually invests in its own facilities, it becomes more effective competitor. This, in turn, decreases the retail prices and boosts the diffusion process. Hence, the probability of a successive upside case in the next regulatory review increases. As a result, the proposed approach is consistent with the ladder-of-investment theory when the investment is proven to be successful.

Now, assume that in the next regulatory review $(t=9)$ the cumulative recovery is as expected, i.e. $82 \%$. In this case, the regulator does not change the access price set at the previous regulatory review since it is expected that the reviewed access price at $t=6$ will lead to the recovery of the NGA investment at $t=12$.

\subsection{The end of the clause}

Three different cases concerning the review of the access price has been already examined and discussed. However, the success of the proposed approach is related with its ability to lead the NGA investment to be recovered (at least) at a predetermined period. Thus, a further discrimination between three cases according to whether the NGA investment is recovered earlier, later or at the predetermined period is needed.

When the NGA investment has been fully recovered at $t=T$, the regulator does not make any further payment to the incumbent, the latter stops making indirect periodic payments to the entrant and no regulatory remedies are imposed to the incumbent. This implies that the incumbent is free to set the access price to the recovered NGA networks. If the NGA investment has been fully recovered at $t=T$ due to successive downside cases or because the initially estimated cumulative 
recovery has been very close to the actual one, then the entrant would have probably established a significantly high customer base. It is thus expected that the entrant will invest in its own facilities in order to be active in the market as soon as the clause ends unless the incumbent prices the access too low in order to avoid intense facilities-based competition.

Furthermore, if the NGA investment has been fully recovered at $t=T$ due to successive upside cases, then increasing access prices would have led to intense facilities-based competition. It is expected that the end of the clause does not significantly affect the entrant's investment incentives since the entrant would have already climbed many rungs of the investment ladder. This implies that the new entrant will be based on its own infrastructure rather than on incumbent's one for serving its consumers, thereby rendering the unregulated access price of limited significance. In these cases, the NGA investment may have been also recovered before the predetermined period.

Although we believe that the proposed approach will eventually lead to the recovery of the NGA investment at $t=T$ or even earlier, we cannot exclude the possibility that the NGA investment would have not been recovered at the end of the predetermined period $T$. Assume that the actual cumulative recovery at $t=T$ is lower than the initially estimated one $\left(D_{T}=100 \%\right)$. In this case, the default event occurs and the regulator compensates the incumbent for the unrecovered part of the NGA investment which is given by $\left(100 \%-D_{T}^{\text {actual }}\right.$ )(investment cost). Using the numerical example of Section 4.3 .4 , we assume that at $t=12$ the CDS approach has fulfilled in recovering only a part of the investment cost. For instance, if the actual cumulative recovery of the investment at $t=12$ is $70 \%$, then the regulator should compensate the incumbent for the unrecovered part which is $\left(100 \%-D_{T}^{\text {actual }}\right) F=\left(30 \times 10^{10}\right) / 100=3 \times 10^{9}$.

The difference $\left(D_{T}-D_{T}^{\text {actual }}\right)$, which is closely related to the upside or downside cases in the previous regulatory reviews, significantly affects the entrant's investment incentives and the subsequent competition level after the end of the clause. The reason is that after that time no regulatory remedies will be imposed to the incumbent, and hence, the entrant will not have access to the incumbent's NGA networks at regulated prices. One should further discriminate between three cases according to the difference $\left(D_{T}-D_{T}^{\text {actual }}\right)$.

Firstly, if in the previous regulatory reviews there were successive upside cases, this difference should be low enough and the diffusion process should have reached its saturation level. Hence, the entrant would have already climbed many rungs of the investment ladder and the end of the clause will incentivize the entrant to be a facilities-based competitor.

Secondly, if in the previous regulatory reviews there were successive downside or base cases which have led the entrant to build a critical market share due to low access prices, then the difference $\left(D_{T}-D_{T}^{\text {actual }}\right)$ is expected to be low enough, and hence, the entrant will probably invest in its own facilities in order to continue being active in the market.

However, if the low access prices have failed to induce the entrant to increase its market share due to the low demand for the new fiber-based services, then the difference would be high enough, the incumbent's market share would be also low and the proposed approach would fail to promote facilities-based competition over NGA networks.

It is obvious that regardless of the unrecovered part of the investment, public funds will be used in order to compensate the incumbent. Therefore, one could argue that the proposed CDS approach privatizes profits and socializes losses by allowing the regulator to bear part of the investment risk. For this reason, the next section discusses the economic rationale of the proposed approach.

\subsection{The economic rationale of the CDS approach}

Although the regulatory intervention at predetermined periods ensures that the cumulative recovery process will not deviate significantly from the initially estimated one, the possibility of a default event cannot be excluded. The existence of such probability implies that the proposed CDS approach may privatize profits and socialize losses by allowing the regulator to bear part of the investment risk. In other words, public funds may be used for compensating private investments in NGA networks. Therefore, the regulator should compare the costs and the benefits of bearing part of the investment risk from a social perspective. ${ }^{14}$ Obviously, the social cost of the CDS approach is the amount of compensating the incumbent in the case that the NGA investment has not been recovered after $T$ years. If social benefits outweigh social costs, then the regulator is willing to bear part of the investment risk.

According to the EC (2010b) "the EU single market for electronic communications services, and in particular the development of very high-speed broadband services, is key to creating economic growth and achieving the goals of the Europe 2020 strategy. The fundamental role of telecommunications and broadband deployment in terms of EU investment, job creation and overall economic recovery was notably highlighted by the European Council in the conclusions of its March 2009 meeting". In addition, referring to work undertaken by the OECD (2009), the EC (2010c) states that "the cost savings in just four sectors of economy (transport, health, electricity and education) would justify the construction of a national fiber-to-the-home (FTTH) network". It is thus obvious that "the social benefits from investment in digital infrastructures by far exceed the private incentive for investment" (EC, 2011). The reason is that like many infrastructure investments, NGA networks may create positive spill-over effects that are not captured in any individual user's willingness-to-pay. This implies a clear public policy case for governments to facilitate the roll out of NGA networks by reducing the risk for the investor (DotEcon, 2012). Therefore,

\footnotetext{
${ }^{14}$ Although in the economic terminology social surplus includes both industry profits and consumer surplus, we use the term social surplus as meaning consumer surplus (i.e. excluding private costs and benefits) in order to emphasize that the socialization of the losses is referred to the part of the losses which are funded by the consumers (not the firms) in the NGA market.
} 
when there are significant social benefits stemming from NGA investments but the private investment incentives are weak, the regulator should bear part of the investment risk in order to encourage the wide deployment of NGA networks. This view is also expressed in the Digital Agenda for Europe (EC, 2010a): "without strong public intervention there is a risk of a suboptimal outcome, with fast broadband networks concentrated in a few high-density zones with significant entry costs and high prices. The spill-over benefits created by such networks for the economy and the society justify public policies guaranteeing universal broadband coverage with increasing speeds".

Recent empirical studies have tried to quantify the positive impact of investing in broadband infrastructures on the main economic and social indices, with the research focus shifting towards the impact of higher speed services. Considering that broadband penetration may be endogenous to the growth process Czernich et al. (2011) estimate the effect of broadband infrastructure investments on economic growth in the panel of OECD countries in 1996-2007. They find that after a country had introduced broadband, GDP per capita was $2.7-3.9 \%$ higher on average than before its introduction. In terms of subsequent diffusion, an increase in the broadband penetration rate by $10 \%$ points raised annual growth in per capita GDP by $0.9-1.5 \%$ points. Furthermore Katz et al. (2010) estimate the impact of broadband infrastructure investments on German employment and economic output, following the government's National Broadband Strategy that extends through 2014 and the subsequent ultra-broadband evolution from 2015 to 2020. They find that a total investment of close to 36 billion euros in broadband infrastructures would generate a total of approximately 1 million incremental jobs and an additional value added of 33.4 billion euros, while network externalities would result in an additional 137.5 billion euros. In total, this results in 170.9 billion euros of additional GDP (0.60\% GDP growth) in Germany.

It can thus be concluded that broadband connectivity is widely accepted as strategically important not only because of its ability to accelerate the contribution of information and communications technology (ICT) to economic growth (Teppayayon \& Bohlin, 2010), but also because network investments are potentially important targets of public investment during downturns as a way to increase demand and employment (Reynolds, 2009). These results have encouraged national government around the world to be actively involved in the deployment of regional or nationwide NGA networks by adopting various subsidization strategies (Cave \& Hatta, 2009; DotEcon, 2012; Kenny \& Kenny, 2011; Ruhle, Brusic, Kittl, \& Ehrler, 2011). Such supply-side policies exert a positive impact on penetration and economic growth at the initial stages of the diffusion process, thus justifying their use in the deployment of NGA networks (Belloc, Nicita, \& Rossi, 2012). These initiatives imply that social benefits not only exceed the private incentive for investments, but also the potential social costs. Therefore, governments are willing to use public funds in order to either deploy state-owned NGA networks or subsidy private investments in such networks, although there is a risk of socializing losses. It is thus obvious that the expected social benefits from the deployment of NGA networks are much greater than the part of the deployment cost which is financed by public funds.

In the proposed CDS approach the social costs are even lower since the regulator compensates the incumbent only for the unrecovered part of the NGA investment and only in the case that the investment has not been recovered after a predetermined period. Unlike the governments' subsidization strategies which use the public funds ex-ante (and thus regardless of the success of the investment), the proposed approach correlates the amount of the public funds used with the success of the investment. In particular, the more successful the investment is, the lower the amount of the public funds used for financing the NGA investment. Therefore, the expected social costs, which ex-post stem from the CDS approach, are lower than the social costs of ex-ante (partially or wholly) subsidizing a given NGA investment. As a result, the difference between social benefits and costs is even higher, which means that the adoption of the CDS approach is clearly justified in social terms.

The basic mechanism used by the CDS approach to reduce (or even to annihilate) the amount of public funds used to compensate the incumbent is to make the new entrant receive a subsidy equal to the fictitious costs of the credit default insurance. From the incumbent's point of view such subsidy is irrelevant since it does not affect its profits (ceteris paribus). Indeed, the incumbent considers the entrant's subsidy as cost either if it takes the form of the credit default insurance or the form of a reduction in the access payments. Obviously, the entrant's profits increase but the variation in the access price, which depends on the success of the NGA investment, makes the entrant an effective service-based competitor in the downside cases and an effective facilities-based competitor in the upside cases. This result has a twofold implication. Firstly, not only the incumbent forgoes revenues from the access market in order to minimize the investment risk, but also it forgoes revenues from the retail market due to the intensification of competition. Therefore, the proposed CDS approach works pretty much in the same way as the financial CDS contract in which a protection buyer minimizes its investment risk by forgoing some of its future profits. ${ }^{15}$ Secondly, the proposed CDS approach maximizes the potential efficiency outcomes taking into account the existing conditions in the NGA market. Of course, these efficiency outcomes have a strong positive impact on consumer surplus. In other words, the indirect subsidization of the entrant increases consumer surplus, and hence, social benefits outweigh social costs.

It should be noted that this result does not necessarily imply that the proposed CDS approach maximizes social welfare. In fact, it provides a theoretical approach to encourage the deployment of a nationwide NGA network (i.e. maximize the potential investment outcome in terms of geographic coverage) with the ambition that such deployment will finally reflect

${ }^{15}$ The Appendix provides an example of a financial CDS contract and relates the outcomes with the application of the CDS approach in the NGA market. 
the socially desirable choice as reflecting in an effective migration path towards facilities-based competition over NGA networks.

\subsection{Implementation issues and limitations}

The proposed model describes a feasible way to initially encourage the incumbent to invest in new fiber-based access networks and then to induce facilities-based competition over NGA networks. The access pricing scheme ensures that the access is provided at cost-based prices including a risk premium. In the proposed model, the regulator not only eliminates the uncertainty of the NGA investment, but also the uncertainty of the usefulness of the risk premium. ${ }^{16}$ For this reason, the risk premium is subtracted from the cost-based access price. This definition implies that the cost-based access price of the NGA networks represents the highest access charge that the entrant may pay to the incumbent. However, we should keep in mind that a cost-based access price does not necessarily implies a low access cost since: (i) the cost of providing the access to the NGA networks is much higher than the respective level of copper networks, and (ii) the level of the cost-based access price depends on the applied costing methodologies (DotEcon, 2012). Furthermore, the implementation of the CDS approach focuses on the impact of a change in the access price (regardless of its nominal value) on the recovery of the NGA investment and on the entrant's incentives to invest in its own NGA network. Therefore, the proposed CDS approach can be also used in the cases where the initial access price is higher or lower than the cost-based access price.

In addition, the flexibility of the regulator to review the risk premium following certain rules tackles the additional tradeoff between the positive effects of greater certainty on investment incentives and possible negative effects of erroneous intervention on welfare. The rules under which the regulator review the access price ensure that such price increases over time as long as the investment is successful. This implies that the proposed model reflects an application of the ladder-ofinvestment theory, and hence, it succeeds in inducing facilities-based competition over NGA networks. It is thus obvious that the success of NGA investments is a necessary, but not a sufficient, condition for the application of the ladder-ofinvestment theory. The reason is that even if the investment is successful, a decreasing access price reflecting the lower demand uncertainty increases the entrant's opportunity cost of investing in its own facilities, and thus dilutes the entrant's investment incentives. From the above analysis it can be deduced that the proposed approach is aligned with the four basic principles of the current regulatory framework in the European NGA market.

Hitherto we have limited our analysis to the case in which one investor has undertaken a nationwide NGA deployment. However, it is widely known that both market and geographic characteristics affect the profitability of an NGA investment. In particular, potential investors are willing to deploy fiber access networks in the areas which are characterized by high population density and high GDP per capita. The former factor ensures low investment cost, whereas the latter is positively correlated with the consumers' willingness-to-pay for the new fiber-based services. This implies that both market and geographic conditions have already led to differences in the degree of NGA deployment not only across countries, but also across areas within a given country. In these cases, the CDS approach can be applied to encourage the deployment of NGA networks in the rest geographic areas either in an integrated or in a fragmented way. In the former case, the regulator and an investor agree on a business plan that allows a single investor to recover the NGA investment in the rest geographic areas. In the latter case, the regulator agrees on many business plans with different investors each of them being willing to invest in a specific geographic area in a country.

The variety of local market and geographic conditions is reflected in the resulted regulatory remedies of the CDS approach. For instance, in the more densely populated areas the deployment of NGA networks is more profitable from an investor's perspective, and hence, the CDS approach results in higher access prices and shorter period of access regulation. On the contrary, in the less densely populated areas, the probability of default is higher, and hence, the CDS approach results in lower access prices which promotes entry by alternative operators in order to boost the diffusion process. In addition, the existence of a strong cable industry in a country implies that the nationwide NGA deployment creates a facilities-based competition between the investor and the cable company. This result has a positive effect on consumers' willingness-to-pay, and therefore, to the diffusion process. Put differently, successive upside cases are expected which, in turn, lead to high access prices. This outcome is socially desirable since facilities-based competition is preferred than service-based competition which is promoted by low access prices. It can thus be deduced that the proposed CDS approach is scalable and consistent with the view of BEREC (2011) concerning the different regulatory treatment across countries or geographic areas when there are significant national or regional differences in terms of population density, willingness-to-pay, inter platform competition etc.

Although the proposed CDS approach seems to facilitate the deployment of fiber-based access networks and the gradual migration from service-based to facilities-based competition over NGA networks, there are some limitations that should be further investigated.

Firstly, the proposed approach does not take into account the impact of the bargaining power of the two parties in the contract on the periodically reviewed access price. In particular, the proposed approach implicitly assumes that both parties have the same bargaining power which does not change during the predetermined period. It is obvious that since the bargaining power of either the regulator or the incumbent may change as a result of the implementation of the CDS

\footnotetext{
${ }^{16}$ According to ETNO (2008), the risk premium reimburses the incumbent only when the investment is successful. Therefore, in the downside cases the usefulness of the risk premium is of limited importance.
} 
approach, the impact of such change on the access prices, and thus, on the cumulative recovery process should be further explored.

Secondly, the major shortcoming of the proposed approach is the assumption that the regulator has full information about the evolution of the main demand and cost parameters. However, potential investors have an incentive to misrepresent information, such as to increase the total cost of the investment and to shorten the reasonable period for the recovery of the investment in order to be over-compensated for the unrecovered part of the investment and then reap the benefits of being the first-mover. It is thus obvious that there are many informational requirements, and hence, regulators should oblige the investor to provide information about its business operation and its network structure. Both BEREC (2011) and the EC recommendation envision such transparency, especially for the technical characteristics and the geographical location of the investor's network. This implies that regulators should incentivize operators to provide the actual information about the access networks. In particular, regulators should crosscheck the provided information by applying various costing methodologies, cooperate with audit companies in order to retrieve financial statements and intensify quality and competition tests. When it is found that the provided information significantly deviates from the actual one, then the regulator should penalize the investor for misrepresenting information. ${ }^{17}$ Therefore, if both the probability of finding such misrepresentation and the subsequent penalty are high, then the investor does not have significant incentives to misrepresent information.

Although such a regulatory treatment enables the regulators to properly assess the actual investment cost, it also makes regulatory agencies act as operators which are willing to invest in NGA network. This argument is enhanced by the proposed approach in which regulatory agencies are actively involved in business decisions concerning the expected profitability of deploying an NGA network taking into account the cost and the timing of such investments, the risk of the specific investment project and the periodic payments that correspond to the default event. Put differently, regulators should expertise in business and management decisions which implies a slippery slope from setting the rules under which incumbents and entrants operate toward micro-management of investments...

\section{Conclusions}

This paper initially showed that the regulatory policy which aims to stimulate competition in the market by facilitating entry of alternative operators, promotes static efficiency at the cost of dynamic efficiency. Thus, it reviewed the EC Recommendation on regulated access to NGA (EC, 2010b) which provides the NRAs with guidelines for tackling this tradeoff, as well as, the research articles which propose new regulatory approaches that may promote both static efficiency and investments in NGA networks. It was found that: (i) there is no consensus about the optimal regulatory policy that promotes competition and encourages investments in NGA networks; and (ii) the reviewed research articles are not consistent with the current regulatory framework in the European NGA market as described by the EC Recommendation in terms of both the evolution of the regulatory goals over time (i.e. encourage the incumbents to invest in new fiber-based access networks without distorting service-based competition, and then encourage the access seekers to invest in their own fiber infrastructures) and the proposed regulatory settings (i.e. the characteristics of the access pricing formula, the evolution of the access price over time and the provision of regulatory certainty).

Therefore, the goal of this paper was twofold. In particular, it aimed to develop a new regulatory approach which reflects the current European NGA framework and tackles the trade-off between promoting competition and encouraging investments. It was shown that under plausible assumptions the proposed approach, which is based on the basic principles governing a Credit Default Swap (CDS), tackles the initial trade-off between encouraging the incumbent to invest in NGA networks and fostering competition, while it incentivizes the entrant to gradually climb the ladder-of-investment. This implies that the proposed approach represents an effective way towards facilities-based competition over NGA networks.

The main innovation of this paper was the application of a pure financial tool to the field of regulatory economics. For this reason, the migration from copper access networks to NGA networks was studied under quite general but plausible assumptions. For example, the proposed CDS approach was based on the assumption that the cumulative recovery process is analogous to the diffusion process of the fiber-based services. Although this is a plausible assumption, a more rigorous techno-economic analysis, which takes into account all factors that affect each provider's profits, is needed. In addition, numerical calculations of the evolution of the probability of default and its impact on access prices, investment incentives and competition are also needed.

It is thus obvious that this paper also aims to trigger a fruitful open discussion about its implementation limitations and its effectiveness on inducing facilities-based competition over NGA networks. The starting point of this discussion should unambiguously be the need for an extensive review of the existing legislation regarding the legal authorities of the regulatory agencies. The current framework seems to provide legal restrictions on regulators to sign such CDS contracts that may result in the subsidization of the investors by using public funds. Therefore, the question of whether regulatory agencies should have the jurisdiction to sign such contracts deserves more attention and requires further investigation.

\footnotetext{
${ }^{17}$ We would like to thank Professor Martin Cave for a private conversation about this issue at the 19th ITS Biennial Conference.
} 


\section{Acknowledgments}

We would like to thank Nikos Chostelidis, CFA and Dr. Dimitris Katsianis for their useful remarks and comments. We also thank the Guest Editor, Johannes Bauer, as well as the three anonymous referees, for precious comments that considerably improved the manuscript. Markos Tselekounis also acknowledges financial support from the European Union (European Social Fund - ESF) and Greek national funds through the Operational Program "Education and Lifelong Learning" of the National Strategic Reference Framework (NSRF) - Research Funding Program: Heracleitus II. Investing in knowledge society through the European Social Fund.

\section{Appendix A}

The model works pretty much in the same way as the CDS protection bought in the financial market. Let's assume a simplified example in which a financial institution A invests $10 \mathrm{M} €$ in an investment grade corporate bond with annual coupon payment of $6 \%$ and 10 years to maturity. At the day of purchase, the corporate bond is downgraded to a speculative rating. To avoid selling on loss, the financial institution decides to enter into CDS with a financial institution B, with a $3 \%$ spread paid annual on face amount of $10 \mathrm{M} €$. The following happens:

- The financial institution A receives each year 6\% coupon payment on $10 \mathrm{M} €$ i.e. $600,000 €$.

- The financial institution A pays each year CDS premium of $3 \%$ on $10 \mathrm{M} €$ i.e. $300,000 €$ to the financial institution B.

- In the case of default the financial institution A receives from the financial institution B $10 \mathrm{M} €$.

- In the case of no default the financial institution A receives the face amount of $10 \mathrm{M} €$ from the issuer of the bond.

What happens in the above case is that the financial institution A has no risk at all no matter what the outcome of the investment is. It only gives up a premium of $300,000 €$, which can be seen from our model's perspective as the part that incumbent forgoes when agreeing to consider the regulatory parameter $R_{t}$ in the access pricing model.

\section{References}

Alleman, J., Madden, G., \& Kim, H. (2008). Real options methodology applied to the ICT sector: A survey. Communications and Strategies, 70, 27-44. ARCEP (2007). Rapport public d' activite 2006. Available from: 〈http://www.ladocumentationfrancaise.fr/var/storage/rapports-publics//074000424/0000.pdf .

Armstrong, M. (2002). The theory of access pricing and interconnection. In S. K. Martin Cave, Majumdar, \& I. Vogelsang (Eds.), Handbook of telecommunications economics: Vol. 1, structure, regulation and competition (pp. 295-386). Amsterdam: North Holland.

Arora, N., Gandhi, P., \& Longstaff, F. (2012). Counterparty credit risk and the credit default swap market. Journal of Financial Economics, 103(2), 280-293.

Avenali, A., Matteucci, G., \& Reverberi, P. (2010). Dynamic access pricing and investment in alternative infrastructures. International Journal of Industrial Organization, 28(2), 167-175.

Bacache, M., Bourreau, M., \& Gaudin, G. (2011). Dynamic entry and investment in new infrastructures: Empirical evidence from the telecoms industry. Telecom ParisTech working paper no. ESS-11-01. Available from: 〈http://papers.ssrn.com/sol3/papers.cfm?abstract_id=1750217〉.

Belloc, F., Nicita, A., \& Rossi, A. (2012). Whither policy design for broadband penetration? Evidence from 30 OECD countries. Telecommunications Policy, 36 (5), 382-398.

BEREC (October 2011). Report on the implementation of the NGA-recommendation. Available from: 〈http://berec.europa.eu/doc/berec/bor 11 43.pdf〉.

Bouckaert, J., van Dijk, T., \& Verboven, F. (2010). Access regulation, competition, and broadband penetration: An international study. Telecommunications Policy, 34(11), 661-671.

Bourreau, M., Cambini, C., \& Dogan, P. (2012). Access pricing, competition, and incentives to migrate from 'old' to 'new' technology. International Journal of Industrial Organization, 30(6), 713-723.

Bourreau, M., Cambini, C., \& Doğan, P. (2013). Access regulation and the transition from copper to fiber networks in telecoms. EUI working paper RSCAS 2013/ 52. Available from: 〈http://cadmus.eui.eu/bitstream/handle/1814/27597/RSCAS_2013_52.pdf?sequence=1〉.

Bourreau, M., Cambini, C., \& Hoernig, S. (2012). Ex-ante regulation and co-investment in the transition to next generation access. Telecommunications Policy, 36(5), 399-406.

Bourreau, M., \& Doğan, P. (2005). Unbundling the local loop. European Economic Review, 49(1), $173-199$.

Bourreau, M., \& Doğan, P. (2006). "Build-or-buy" strategies in the local loop. American Economic Review, 96(2), 72-76.

Bourreau, M., Doğan, P., \& Manant, M. (2010). A critical review of the "ladder of investment" approach. Telecommunications Policy, 34(11), 683-696.

Bourreau, M., \& Drouard, J. (2010). Stepping Stone or Stonewall? Progressive Entry and the Incentives to Invest in Alternative Infrastructures. Telecom ParisTech working paper no. ESS-10-07. Available from: 〈http://papers.ssrn.com/sol3/papers.cfm?abstract_id=1662402〉.

Bourreau, M., Lupi, P., \& Manenti, F. (2013). Old Technology Upgrades, Innovation, and Competition in Vertically Differentiated Markets. Marco Fanno working paper no. 158. Available at: 〈http://papers.ssrn.com/sol3/papers.cfm?abstract_id=2217525〉.

Brito, D., Pereira, P., \& Vareda, J. (2010). Can two-part tariffs promote efficient investment on next generation networks?. International Journal of Industrial Organization, 28(3), 323-333.

Brito, D., Pereira, P., \& Vareda, J. (2012). Incentives to invest and to give access to non-regulated new technologies. Information Economics and Policy, 24(3-4), $197-211$.

Cambini, C., \& Jiang, Y. (2009). Broadband investment and regulation: A literature review. Telecommunications Policy, 33(10-11), 559-574.

Cambini, C., \& Silvestri, V. (2012). Technology investment and alternative regulatory regimes with demand uncertainty. Information Economics and Policy, 24 $(3-4), 212-230$.

Cave, M. (2006). Encouraging infrastructure competition via the ladder of investment. Telecommunications Policy, 30(3-4), $223-237$.

Cave, M., \& Hatta, K. (2009). Transforming telecommunications technologies-policy and regulation. Oxford Review of Economic Policy, 25(3), 488-505.

Cave, M., \& Vogelsang, I. (2003). How access pricing and entry interact. Telecommunications Policy, 27(10-11), 717-727.

Cave, M., Fournier, A., \& Shutova, N. (2012). The price of copper and the transition to fiber. Communications E' Strategies, 85, $147-168$.

Charalampopoulos, G., Katsianis, D., \& Varoutas, D. (2011). The option to expand to a next generation access network infrastructure and the role of regulation in a discrete time setting: A real options approach. Telecommunications Policy, 35(9-10), 895-906.

Czernich, N., Falck, O., Kretschmer, T., \& Woessmann, L. (2011). Broadband infrastructure and economic growth. The Economic Journal, 121, 505-532.

De Bijl, P., \& Peitz, M. (2002). Regulation and entry into telecommunications markets. Cambridge: Cambridge University Press. 
Denni, M., \& Gruber, H. (2007). The diffusion of broadband telecommunications in the US: The role of different forms of competition. Communications $\mathcal{E}$ Strategies, 68, 139-157.

Distaso, W., Lupi, P., \& Manenti, F. (2006). Platform competition and broadband uptake: Theory and empirical evidence from the European union. Information Economics and Policy, 18(1), 87-106.

Distaso, W., Lupi, P., \& Manenti, F. (2009). Static and dynamic efficiency in the european telecommunications market. The role of regulation on the incentives to invest and the ladder of investment. In Lee (Ed.), Handbook of research on telecommunications planning and management. U.S.A.: IGI Global (Regulation).

Dixit, A., \& Pindyck, R. S. (1994). Investment under uncertainty (pp. 1-40)Princeton, NJ: Princeton University Press1-40.

DotEcon (July 2012). Regulatory policy and the roll-out of FTTH networks. A report for the FTTH Council Europe. Available from: 〈http://www.ftthcouncil.eu/ documents/Reports/Dot-econ_Regulatory_Report.pdf>.

EC (European Commission) (2000). Commission regulation no. 2887/2000 on unbundled access to the local loop. Available from: 〈http://eur-lex.europa.eu/ LexUriServ/LexUriServ.do?uri=OJ:L:2000:336:0004:0008:EN:PDF>.

EC (European Commission) (2010a). A digital agenda for Europe. Available from:〈http://ec.europa.eu/information_society/digital-agenda/publications/ index_en.htm>.

EC (European Commission) (2010b). European commission recommendation on regulated access to Next Generation Access Networks (NGA). Available from: 〈http://eur-lex.europa.eu/LexUriServ/LexUriServ.do?uri=OJ:L:2010:251:0035:0048:EN:PDF〉.

EC (European Commission) (2010c). European broadband: investing in digitally driven growth. Available from: 〈http://ec.europa.eu/information_society/ activities/broadband/docs/bb_communication.pdf $>$.

EC (European Commission) (2011). Proposal for a regulation of the European parliament and the council establishing the connecting Europe facility. Available from: 〈http://ec.europa.eu/commission_2010-2014/president/news/speeches-statements/pdf/20111019_2_en.pdf〉.

ERG (2005). Broadband market competition report (05-23). Available from: 〈http://www.irg.eu/streaming/erg_05_23_broadbd_mrkt_comp_report_p.pdf? contentId=543362\&field=ATTACHED_FILES $\rangle$.

ERG (2006). Revised ERG common position on remedies - Explanatory memorandum (06-19). Available from: 〈http://www.irg.eu/template20.jsp? categoryld $=260348 \&$ contentId $=544952\rangle$.

ERG (June 2009). Report on Next Generation Access - Economic Analysis and Regulatory Principles. Available from: 〈http://www.erg.eu.int/doc/ publications/erg_09_17_nga_economic_analysis_regulatory_principles_report_090603_v1.pdf).

ETNO (2008). ETNO Reflection Document in response to the Commission Recommendation on regulated access to Next Generation Access Networks (NGA). ETNO synthesis paper SP295. Available from:〈http://ec.europa.eu/information_society/policy/ecomm/doc/library/public_consult/nga/etno_sp295.pdf〉.

FCC (Federal Communications Commission) (1996). Telecommunications Act of 1996, Pub. LA. no. 104-104, 110 Stat. 56. Available from: 〈http://transition. fcc.gov/telecom.html .

FCC (Federal Communications Commission) (2010). Connecting America: The national broadband plan. Available from: 〈http://www.broadband.gov/ download-plan/>.

Foros, Ø. (2004). Strategic investments with spillovers, vertical integration and foreclosure in the broadband access market. International Journal of Industrial Organization, 22(1), 1-24.

Franklin, S. L., \& Diallo, M. (2013). Real options and cost-based access pricing: Model and methodology. Telecommunications Policy, 37(4-5), 321-333.

Gavosto, A., Ponte, G., \& Scaglioni, C. (2007). Investment in next generation networks and the role of regulation: A real options approach. ISEG-UTL economics working paper no. 031/2007/DE. Available from: 〈http://papers.ssrn.com/sol3/papers.cfm?abstract_id=1080564〉.

Grajek, M. and L.H. Röller (2009). The effect of regulation on investment in network industries: Evidence from European telecoms. ESMT working paper no. 09-004. Available from: 〈https://www.esmt.org/fm/479/ESMT-09-004.pdf〉.

Greenstein, S., \& McDevitt, R. (2009). The broadband bonus: Accounting for broadband Internet's impact on US GDP. NBER working paper no. 14758. Available at: 〈http://www.nber.org/papers/w14758〉.

Höffler, F. (2007). Cost and benefits from infrastructure competition. Estimating welfare effects from broadband access competition. Telecommunications Policy, 31(6-7), 401-418.

Hori, K., \& Mizuno, K. (2006). Access pricing and investment with stochastically growing demand. International Journal of Industrial Organization, 24(4), $795-808$.

Hori, K., \& Mizuno, K. (2008). Competition schemes and investment in network infrastructure under uncertainty. Journal of Regulatory Economics, 35(2), $179-200$.

Inderst, R., \& Peitz, M. (2012a). Network investment, access and competition. Telecommunications Policy, 36(5), 407-418.

Inderst, R., \& Peitz, M. (2012b). Market asymmetries and investments in next generation access networks. Review of Network Economics, 11, 1.

ITU (April 2012). The impact of broadband on the economy: Research to date an policy issues. Available from: 〈http://www.itu.int/ITU-D/treg/broadband/ ITU-BB-Reports_Impact-of-Broadband-on-the-Economy.pdf $\rangle$.

Katz, R., Vaterlaus, S., Zenhäusern, P., \& Suter, S. (2010). The impact of broadband on jobs and the German economy. Intereconomics, 45(1), 26-34.

Kenny, R., \& Kenny, C. (2011). Superfast broadband: Is it really worth a subsidy?. Info, 13(4), 3-29.

Klumpp, T., \& Su, X. (2010). Open access and dynamic efficiency. American Economic Journal: Microeconomics, 2, 64-96.

Kotakorpi, K. (2004). Access price regulation, investment and entry in telecommunications. International Journal of Industrial Organization, 24(5), 1013-1020.

Koutroumpis, P. (2009). The economic impact of broadband on growth: A simultaneous approach. Telecommunications Policy, 33(9), 471-485.

Longstaff, F. A., Mithal, S., \& Neis, E. (2005). Corporate yield spreads: Default risk or liquidity? New evidence from the credit. The Journal of Finance, 60(5), $2213-2253$.

Michalakelis, C., Varoutas, D., \& Sphicopoulos, T. (2008). Diffusion models of mobile telephony in Greece. Telecommunications Policy, 32(3-4), 234-245.

Moore, G. (1991). Crossing the chasm. Harper Business Essentials, New York.

Neumann K.-H. and Vogelsang I., How to price the unbundled local loop in the transition from copper to fiber access networks?, TelecommunicationsPolicy, ISSN 0308-5961, http://dx.doi.org/10.1016/j.telpol.2013.05.011, in press. ISSN 0308-5961.

Nitsche, R., \& Wiethaus, L. (2011). Access regulation and investment in next generation networks - A ranking of regulatory regimes. International Journal of Industrial Organization, 29(2), 263-272.

OECD (2009). Network developments in support of innovation and user needs. Available from: /http://search.oecd.org/officialdocuments/displaydocu mentpdf/?doclanguage $=$ en $\&$ cote $=$ dsti/iccp $/ \operatorname{cisp}(2009) 2 /$ final $>$.

Oldale, A., \& Padilla, J. (2004). From state monopoly to the "investment ladder": competition policy and the NRF. Swedish competition authority series: The pros and cons of antitrust in deregulated markets. Stockholm.

OPTA (19 December 2008). Policy rules tariff regulation for unbundled fiber access. The Hague. Available from: 〈http://www.opta.nl/en/news/all-publications/ publication/?id=2832 $>$.

OPTA (May 2010). Regulation, risk and investment incentives, regulatory policy note 06. Available from: 〈http://www.opta.nl/en/news/all-publications/ publication/?id=3201>.

Pindyck, R. S. (2007). Mandatory unbundling and irreversible investment in telecom networks. Review of Network Economics, 6(3), 274-298.

Reynolds, T. (2009). The role of communications infrastructure investment in economic recovery (DSTI/ICCP/CISP (2009) 1/FINAL) policy. Paris. Available from: 〈http://www.oecd.org/dataoecd/4/43/42799709.pdf〉.

Ruhle, E.-O., Brusic, I., Kittl, J., \& Ehrler, M. (2011). Next generation access (NGA) supply side interventions-An international comparison. Telecommunications Policy, 35(9-10), 794-803.

Sarmento, P., \& Brandao, A. (2007). Access pricing: A comparison between full deregulation and two alternative instruments of access price regulation, costbased and retail-minus. Telecommunications Policy, 31(5), 236-250. 
Shumate, P. W. (2008). Fiber-to-the-home: 1977-2007. Journal of Lightwave Technology, 26(9), 1093-1103.

Teppayayon, O., \& Bohlin, E. (2010). Broadband universal service in Europe: Review of policy consultations 2005-2010. Communications and Strategies, 80, $21-42$.

Tselekounis, M., Maniadakis, D., \& Varoutas, D. (2013). NGA Investment Incentives under Geographic Price Discrimination. In proceedings of the fortieth EARIE conference, 30 August-1 September 2013. Évora, Portugal (accepted for publication). Available from: 〈http://www.webmeets.com/files/papers/ earie/2013/258/EARIE2013_Tselekounis.pdf).

Tselekounis M. and Varoutas D., Investments in next generation access infrastructures under regulatory uncertainty, Telecommunications Policy, http://dx. doi.org/10.1016/j.telpol.2013.06.001, in press. ISSN 0308-5961.

Tselekounis, M., Varoutas, D., \& Martakos, D. (2012). On the social optimality of make-or-buy decisions. Journal of Regulatory Economics, 41(2), 238-268.

Valletti, T. M. (2003). The theory of access pricing and its linkage with investment incentives. Telecommunications Policy, 27(10-11), 659-675.

Vareda, J. (2011). Quality upgrades and bypass under mandatory access. Journal of Regulatory Economics, 40(2), 177-197.

Vareda, J., \& Hoernig, S. (2010). Racing for investment under mandatory access. The BE Journal of Economic Analysis \& Policy, 10, 1.

Vogelsang, I. (2003). Price regulation of access to telecommunications networks. Journal of Economic Literature, 41(3), 830-862.

Vogelsang, I. (2010). Incentive regulation, investments and technological change. Ifo/CESifo E OECD conference on regulation: Political economy, measurement and effects on performance. Munich, Germany (Vol. 49, pp. 1-38). Munich, January 29-30: CESifo.

WIK (15 July 2009). The economics of next generation access. A study for the European Competitive Telecommunications Association ECTA. Bad Honnef. Available from:〈http://www.wik.org/uploads/media/Ecta_Study_Addendum_2009.pdf〉. 